\title{
AUTOMOBILE COMPONENTS PROCUREMENT USING A DEA-TOPSIS-FMIP APPROACH WITH ALL-UNIT QUANTITY DISCOUNT AND FUZZY FACTORS
}

\author{
Jiajia CHEN ${ }^{1,2}$, Zeshui XU®1 ${ }^{*}$, Xunjie GOU®1, \\ Dongbin HUANG ${ }^{\circledR 2}$, Jianchuan ZHANG ${ }^{(13}$ \\ ${ }^{1}$ Business School, Sichuan University, Chengdu, China \\ ${ }^{2}$ School of Economics and Management, Chongqing University of Posts \\ and Telecommunications, Chongqing, China \\ ${ }^{3}$ SOKON Industry Group Stock Corporation Ltd, Chongqing, China
}

Received 12 February 2019; accepted 17 May 2020

\begin{abstract}
Components procurement is a crucial process in supply chain management of the automobile industry. The problem is further complicated by imprecise information and discount policies provided by suppliers. This paper aims to develop a computational approach for assisting automobile components procurement with all-unit quantity discount policy and fuzzy factors, from potential suppliers offering different product portfolios. We propose a two-stage approach consisting of a DEA-TOPSIS (data envelopment analysis procedures followed with a technique for order preference by similarity to an ideal solution) approach for screening suppliers, and subsequentially a fuzzy mixed integer programming (FMIP) model with multiple objectives for optimizing order allocations. The DEA-TOPSIS approach integrates suppliers' comparative performance and diversity performance into an overall index that improves the ranking of potential suppliers, while the FMIP model features a soft time-window in delivery punctuality and an all-unit quantity discount function in cost. By applying it in a case of automobile components procurement, we show that this two-stage approach effectively supports decision makers in yielding procurement plans for various components offered by many potential suppliers. This paper contributes to integrating multi-attribute decision analysis approach in the form of DEA crossevaluation with TOPSIS and FMIP model for supporting components procurement decisions.
\end{abstract}

Keywords: automobile components procurement, all-unit quantity discount, soft time-window, DEA cross-evaluation, TOPSIS, fuzzy mixed integer programming.

JEL Classification: D81, C61.

*Corresponding author. E-mail: xuzeshui@263.com 


\section{Introduction}

Influenced by the global financial crisis occurring in 2008, the automobile industry is facing unprecedented challenges (Sturgeon et al., 2013). Automobile manufacturers are confronted with various threats such as profit shrink, increasing risk, growth of cost and uncertain environments. In order to reduce the procurement risk and cut down the total cost of the supply chain, a large number of automobile manufacturers have begun to downscale their supplier base. As one of the world's largest automobile manufacturers, Ford steadily reduced suppliers from 2004 to 2011, and its global production suppliers had reduced from 3300 to 1500 (Stein, 2011). Chongqing SOKON Industry Group Stock Corporation Ltd, which is one of the biggest automobile manufacturers in Southwest China, has also begun to reduce its core suppliers recently. Most automobile manufacturing enterprises are aiming to own high-quality supplier base that consists of top performance suppliers. Removing the inferior suppliers and developing an advanced procurement approach have become the common goal of automobile companies (Ghadimi et al., 2017).

When automobile companies make procurement decisions, supplier screening and order allocation are two crucial processes to be deliberated (Ghadimi et al., 2017; Trautrims et al., 2017). This is especially the case when there are a great number of potential suppliers. Due to fierce competition, automobile enterprises need to reduce their potential suppliers and seek high-quality candidates to form their supplier base (Stein, 2011). The performance of an automobile supplier at a time is usually reflected by various criteria which include product quality, cost, delivery, service and manufacturing technology, etc. These criteria often provide valuable information and reflect supplier's performance from various perspectives (Homfeldt et al., 2017; Tian et al., 2017). For automotive procurement, different types of components apply various evaluation criteria. Engine component and sensor component, consisting of several sub-components, are two most important types in the supply market. The former contains "crankshaft", "connecting rod", "piston" and "oil injection nozzle", etc., and the latter consists of "intake air pressure sensor", "air flow sensor", "oxygen sensor", "detonation sensor", etc. Suppliers at stake may offer different portfolios of components. Therefore, it is quite demanding for the sourcing department to conduct supplier evaluation with effectiveness in such cases.

The first thing to do for automobile components procurement is supplier screening. With the evaluation criteria provided by automobile manufacturers, the sourcing department needs to apply an appropriate approach to determine which suppliers are to be selected for order allocation; which should be required for improvement and with reduced awards; which should rectify quality accordingly and their quality manager should explain the problems to the buyer; which should be removed from the supplier base. Drawing upon the DEA crossevaluation model proposed by Doyle and Green (1994), Talluri, Decampos and Hult (2013) utilized the DEA cross-efficiency scores as the comparative performance, and defined the other dimension of cross-efficiency evaluation as the diversity performance index in the context of supplier base establishment. These two performance indexes were used to categorize suppliers into groups for supplier rationalization, but a question remains that how to rank the potential suppliers by the two performance indexes simultaneously. 
On top of that, order allocation among the best suppliers follows as the second task. The objectives are usually multiple when allocating orders, for instance, minimizing total cost, delivery in time, best product quality and environmental qualifications, etc. At this step, two facts may be encountered. Firstly, there are several uncertain factors in the procurement such as fuzzy demand, imprecise delivery time and inexact production capacity etc.; these uncertainties are often expressed by fuzzy variables in imprecise terms, e.g. "pessimistic", "most likely" and "optimistic" (Riedl et al., 2013; Zhang \& Chen, 2013; Jin et al., 2014; Shadkam \& Bijari, 2017; Niroomand et al., 2019). For converting the fuzzy information into accurate values to enable computational procedures, this paper integrates the fuzzy theory (Zadeh, 1965; Bellman \& Zadeh, 1970; Tiwari et al., 1987; Sakawa, 1993; Kumar et al., 2004) into the optimization procedures and adopts triangular fuzzy values for the uncertain variables. Secondly, the delivery objective is usually defined by a time window. In order to align delivery time incentive, a time-window mechanism to link delivery time with penalty was proposed by Ioannou, Kritikos and Prastacos (2003), and further developed by Yu and Lin (2012). The time-window based on a mechanism that the products will be returned when delivery time exceeds a certain threshold is not suitable for the automobile industry, in which rejecting components may interrupt production and further cause economic losses.

Discount policy is often practiced when procurement quantities are large, which requires optimization models to be inclusive in this regard (Jahangoshai Rezaee et al., 2017; Pascual et al., 2017; Ucal Sari, 2018). The discount policies include quantity discount, business volume discount and price discount. Quantity discount is the most frequently-used strategy which consists of all-unit quantity discount and incremental quantity discount (Corbett, 2000; Tsai \& Wang, 2010; Zhang \& Chen, 2013; Ghaniabadi \& Mazinani, 2017; Bohner \& Minner, 2017; Manerba \& Perboli, 2019). All-unit quantity discount involves multiple quantity breaks, and buyers get a discount for every unit when the purchase quantity equals or exceeds each threshold (Wang et al., 2019), while incremental quantity discount allows buyers to get a discount only for extra units above predetermined thresholds (Mirzaee et al., 2018). Discount policy is often an important characteristic in the realistic problems of procurement (Cheraghalipour \& Farsad, 2018; Sabouhi et at., 2018).

This paper intends to develop an approach for components-oriented procurement of the automobile industry with uncertain factors and discount policy. Driven by a practical problem of automobile components procurement for Chongqing SOKON Industry Group Stock Corporation Ltd in China, this paper proposes a DEA-TOPSIS-FMIP approach that includes: (a) Supplier screening with DEA-TOPSIS procedures, where the comparative performance and diversity performance yielded from DEA cross-evaluation procedures are integrated with TOPSIS procedures into an overall performance for each supplier; (b) Allocating orders with FMIP optimization procedures, where fuzzy variables and all-unit discount policy are involved. The nature of contributions may be summarized as follows:

1) By utilizing suppliers' comparative performance and diversity performance obtained from DEA cross-evaluation, and integrating them into an overall performance with subsequent TOPSIS procedures, the DEA-TOPSIS approach proposed in this paper reduces the information loss of diversity performance which is usually overlooked in DEA cross-evaluation, and therefore improves the evaluation of suppliers. 
2) By introducing a piecewise function of all-unit quantity discount policy as a part of cost objective, the model proposed in this paper enhances the usability of the FMIP model in the realistic conditions, as discount policies are commonly applied due to market competitions.

3) By aligning reasonable penalty in the time-window for punctuality, instead of sending back products when delivery is beyond time limits, this paper improves the timewindow mechanism, and makes it realistic to implement in practical settings.

The rest of this paper is organized as follows: Section 1 reviews the related literature. Section 2 elaborates the procedures to rank suppliers with the DEA-TOPSIS approach. Subsequently, Section 3 solves the order allocation problem with all-unit quantity discount policy and imprecise information both in objectives and constraints, which altogether form a DEATOPSIS-FMIP approach for the problem at hand. In Section 4, we apply this approach in an automobile procurement case of Chongqing SOKON Industry Group Stock Corporation Ltd in China. In Section 5, we discuss the validity of the proposed approach and the related sensitivity analysis. Finally, we draw our conclusions in last Section.

\section{Literature review}

In components procurement, supplier screening and order allocation are two important procedures and have attracted much attention in the literature. There are three streams of related studies in these regards. The first focuses on evaluating suppliers by using multicriteria decision analysis approaches such as DEA (Data Envelopment Analysis) and TOPSIS (Technique for Order Preference by Similarity to Ideal Solutions); the second relates to the multi-objective optimization model for order allocation with fuzzy factors, both in objectives and constraints; and the third deals with procurement optimization with discount policies.

As a data analysis approach, DEA was proposed by Charnes, Cooper and Rhodes (1978) to measure the efficiency of decision-making units where multiple input and output variables are involved. Doyle and Green (1994) proposed a cross-evaluation model to evaluate the cross-efficiency score of decision-making units for ranking alternatives. Further, Talluri, Decampos, and Hult (2013) suggested that besides the cross-efficiency scores yielded from the DEA cross-evaluation, which is commonly taken as a measure for ranking alternatives, the diversity measure yielded from a cross-evaluation matrix shall also be useful. By using both the cross-efficiency scores and the diversity measure, and assuming that the optimization of cross-efficiency score is to be maximized while that of the diversity measure is to be minimized, they classified a company's supplier base into four categories which include superior performers for long-term partnerships, good overall performers for supplier development, niche performers for supplier development and inferior performers for pruning. Recently, DEA models have been quite often integrated with other methods for selecting suppliers under various circumstances (Zhou et al., 2016; Jauhar \& Pant, 2017; Zarbakhshnia \& Jaghdani, 2018; Park et al., 2018).

TOPSIS is relevant because it is an effective approach for multi-attribute decision analysis, since the previous steps of DEA cross-efficiency evaluation yielded two dimensions of 
information. TOPSIS ranks a finite set of evaluation alternatives by means of their distance to ideal solutions (Hwang \& Yoon, 1981) and has been widely applied to rank suppliers and remains active in recent literature (Arabzad et al., 2015; Freeman \& Chen, 2015; Wu, 2015; Saradhi et al., 2016; Stević et al., 2016; Yang et al., 2017; Bai \& Sarkis, 2018).

For order allocation, Amid et al. (2006) adopted a fuzzy multiple objectives programming (FMOP) model and further constructed a model considering price breaks in Amid et al. (2009). Later, this FMOP model was extended and applied to more sophisticated procurements. For instance, Yu and Lin (2012) introduced a soft time window mechanism in the delivery function of the model; Nazari-Shirkouhi et al. (2013) proposed an interactive two-phase fuzzy multi-objective linear programming (FMOLP) model to solve the sourcing problem under multi-products and multi-prices; Keshavarz Ghorabaee et al. (2017) proposed a new multi-criteria model with environmental considerations for supplier evaluation and order allocation; and Bodaghi et al. (2018) further developed the FMOP model considering customer order scheduling for order-oriented manufacturing supply chain.

The literature on sellers' discount policies is further related to our study. To adapt to the realistic circumstances, Tsai and Wang (2010) assumed that each supplier offers discount policies, and solved the order allocation problem with incremental discount policy as well as all-unit discount policy by using mixed integer linear programming (MILP) formulations. Zhang and Chen (2013) formulated the model with uncertain demand, quantity discounts and fixed selection costs, by using a mixed integer programming (MIP) model. As in all-unit discount policy setting, the MILP model can only solve small-sized instances with effectiveness, Ghaniabadi and Mazinani (2017) proposed a recursive formulation of the MILP model with much improved computational efficiency, even if all candidate suppliers offer discount policies.

We may define the gap that this paper aims to fill by acknowledging that the existing researches in the literature have not properly solved procurement problems when diversity measure, discount policy and fuzzy factors are at hand simultaneously. Given the fact that the procurer evaluates the performance of suppliers completely based on component objects, instead of supply companies, a multiple products procurement plan is indeed calling for a parallel solution for multiple items but with single item models. The benefits of the proposed DEA-TOPSIS-FMIP approach are that it picks up the lost information of diversity performance besides DEA cross-efficiency scores, which improves suppliers ranking practice; as a subsequent process, it improves the usability of order allocation model with realistically aligned time-window mechanism and solves order optimization with piece-wise functions for discount policies and imprecise information, especially for the case of automobile components procurement. Table 1 summarizes the literature and positions this paper by comparing it with available papers.

It is worthy to be reiterated that the proposed model is a single-item mathematical model, but applied for multiple items independently, due to the nature of the procurement decision at hand is component-based or item-to-item. The SI/MI criterion for the other papers in Table 1 are all based on their mathematical formulation.

Therefore, the added values of the proposed approach are that: (1) The DEA-TOPSIS approach successfully integrates the comparative performance and diversity performance of the 
potential suppliers into an overall performance, which contains more complete information and further represents more valuable supplier rankings and categories for decision makers; (2) Integrating the all-unit quantity discount policy and fuzzy factors into the FMIP model enables the usability of the model in practical circumstances; (3) By mixing the DEA-TOPSIS approach and the FMIP model, the procurement problem is appropriately solved with the coexistence of various components, enormous potential suppliers, all-unit quantity discount, fuzzy information and complex evaluation criteria.

Table 1. Relevant literature and contributions on procurements

\begin{tabular}{|c|c|c|c|c|c|c|c|}
\hline \multirow{2}{*}{ Authors } & \multirow{2}{*}{ Objectives } & \multirow{2}{*}{ Techniques } & \multirow{2}{*}{ Discount } & \multicolumn{3}{|c|}{$\begin{array}{c}\text { Model } \\
\text { Specifications }\end{array}$} & \multirow[t]{2}{*}{$\mathrm{CS} / \mathrm{NE}$} \\
\hline & & & & SE & SOA & Item & \\
\hline $\begin{array}{l}\text { Tsai and } \\
\text { Wang (2010) }\end{array}$ & $\begin{array}{l}\text { Total cost, } \\
\text { Quality, Late } \\
\text { deliveries }\end{array}$ & MILP & Price discount & & * & MI & NE \\
\hline $\begin{array}{l}\text { Razmi and } \\
\text { Maghool } \\
\text { (2010) }\end{array}$ & $\begin{array}{l}\text { Purchasing cost, } \\
\text { Total value of } \\
\text { purchasing }\end{array}$ & $\begin{array}{l}\text { Fuzzy bi- } \\
\text { objective model, } \\
\varepsilon \text {-constraint } \\
\text { and Tchebycheff } \\
\text { method }\end{array}$ & $\begin{array}{l}\text { All-unit } \\
\text { quantity } \\
\text { Discount, } \\
\text { Incremental } \\
\text { quantity } \\
\text { discount, } \\
\text { Total business } \\
\text { volume discount }\end{array}$ & & * & MI & $\mathrm{NE}$ \\
\hline $\begin{array}{l}\text { Yu and Lin } \\
(2012)\end{array}$ & $\begin{array}{l}\text { Total product } \\
\text { cost, } \\
\text { Product quality, } \\
\text { Delivery penalty }\end{array}$ & $\begin{array}{l}\text { FMOP, Time } \\
\text { window }\end{array}$ & & & * & MI & $\mathrm{NE}$ \\
\hline $\begin{array}{l}\text { Zhang and } \\
\text { Chen (2013) }\end{array}$ & Total cost & MIP & $\begin{array}{l}\text { All-unit } \\
\text { quantity } \\
\text { discount }\end{array}$ & & * & SI & $\mathrm{NE}$ \\
\hline $\begin{array}{l}\text { Nazari- } \\
\text { Shirkouhi } \\
(2013)\end{array}$ & $\begin{array}{l}\text { Total purchasing } \\
\text { and ordering } \\
\text { costs, Rejected } \\
\text { items, Late } \\
\text { delivered items }\end{array}$ & FMOLP & $\begin{array}{l}\text { Quantity } \\
\text { discount }\end{array}$ & & * & MI & $\mathrm{NE}$ \\
\hline $\begin{array}{l}\text { Memon et al. } \\
\text { (2015) }\end{array}$ & $\begin{array}{l}\text { Total cost, Lead } \\
\text { time, Quality } \\
\text { level, Logistics } \\
\text { system quality, } \\
\text { Delivery level, } \\
\text { Sustainability level }\end{array}$ & $\begin{array}{l}\text { Chance- } \\
\text { constrained goal } \\
\text { programming }\end{array}$ & & * & * & SI & $\mathrm{NE}$ \\
\hline $\begin{array}{l}\text { Mazdeh et al. } \\
\text { (2015) }\end{array}$ & Total cost & $\begin{array}{l}\text { Mixed-integer } \\
\text { non-linear } \\
\text { model }\end{array}$ & $\begin{array}{l}\text { All-unit } \\
\text { quantity } \\
\text { discount, } \\
\text { Incremental } \\
\text { quantity } \\
\text { discount }\end{array}$ & & * & SI & NE \\
\hline
\end{tabular}


Continue of Table 1

\begin{tabular}{|c|c|c|c|c|c|c|c|}
\hline \multirow{2}{*}{ Authors } & \multirow{2}{*}{ Objectives } & \multirow{2}{*}{ Techniques } & \multirow{2}{*}{ Discount } & \multicolumn{3}{|c|}{$\begin{array}{c}\text { Model } \\
\text { Specifications }\end{array}$} & \multirow{2}{*}{$\mathrm{CS} / \mathrm{NE}$} \\
\hline & & & & SE & SOA & Item & \\
\hline $\begin{array}{l}\text { Arabzad et al. } \\
\text { (2015) }\end{array}$ & $\begin{array}{l}\text { Aggregated } \\
\text { weighted value } \\
\text { from SWOT } \\
\text { analysis }\end{array}$ & $\begin{array}{l}\text { Fuzzy TOPSIS, } \\
\text { MILP }\end{array}$ & & * & * & MI & CS \\
\hline $\begin{array}{l}\text { Ayhan and } \\
\text { Kilic (2015) }\end{array}$ & $\begin{array}{l}\text { Total supplier } \\
\text { score }\end{array}$ & $\begin{array}{l}\text { Fuzzy AHP, } \\
\text { MILP }\end{array}$ & $\begin{array}{l}\text { All-unit } \\
\text { quantity } \\
\text { discount }\end{array}$ & * & * & MI & CS \\
\hline $\begin{array}{l}\text { Jadidi et al. } \\
\text { (2015) }\end{array}$ & $\begin{array}{l}\text { Purchasing cost, } \\
\text { Rejects, Late } \\
\text { deliveries }\end{array}$ & $\begin{array}{l}\text { Multi- } \\
\text { choice goal } \\
\text { programming }\end{array}$ & & & * & SI & $\mathrm{NE}$ \\
\hline $\begin{array}{l}\text { Taleizadeh } \\
\text { et al. } \\
(2015)\end{array}$ & Cost, Profit & $\begin{array}{l}\text { Extended EOQ } \\
\text { model }\end{array}$ & $\begin{array}{l}\text { Incremental } \\
\text { quantity } \\
\text { discount }\end{array}$ & & * & SI & $\mathrm{NE}$ \\
\hline $\begin{array}{l}\text { Aktin and } \\
\text { Gergin (2016) }\end{array}$ & $\begin{array}{l}\text { Cost, Total } \\
\text { weighted triple- } \\
\text { bottom-line score, } \\
\text { Effects of order } \\
\text { splitting }\end{array}$ & $\begin{array}{l}\text { Analytic } \\
\text { network process } \\
\text { (AHP), MILP }\end{array}$ & & * & * & MI & CS \\
\hline $\begin{array}{l}\text { Gupta et al. } \\
(2016)\end{array}$ & $\begin{array}{l}\text { Cost, Quality, } \\
\text { Delivery, } \\
\text { Comprehensive } \\
\text { vendor } \\
\text { performance score }\end{array}$ & $\begin{array}{l}\text { Analytic } \\
\text { network } \\
\text { process (AHP), } \\
\text { FMOILP }\end{array}$ & $\begin{array}{l}\text { All-unit } \\
\text { quantity } \\
\text { discount }\end{array}$ & * & * & MI & CS \\
\hline $\begin{array}{l}\text { Hamdan and } \\
\text { Cheaitou } \\
(2017 a)\end{array}$ & $\begin{array}{l}\text { Total cost of } \\
\text { purchasing, } \\
\text { Total value of } \\
\text { purchasing }\end{array}$ & $\begin{array}{l}\text { Fuzzy TOPSIS } \\
\text { and AHP, } \\
\text { Bi-objective } \\
\text { integer linear } \\
\text { programming }\end{array}$ & $\begin{array}{l}\text { All-unit } \\
\text { quantity } \\
\text { discount }\end{array}$ & * & * & SI & $\mathrm{NE}$ \\
\hline $\begin{array}{l}\text { Hamdan and } \\
\text { Cheaitou } \\
(2017 b)\end{array}$ & $\begin{array}{l}\text { Total green value } \\
\text { of purchasing, } \\
\text { Total cost of } \\
\text { purchasing } \\
\end{array}$ & $\begin{array}{l}\text { Fuzzy TOPSIS, } \\
\text { Bi-objective } \\
\text { optimization } \\
\text { model }\end{array}$ & $\begin{array}{l}\text { Incremental } \\
\text { quantity } \\
\text { discount }\end{array}$ & * & * & SI & $\mathrm{NE}$ \\
\hline $\begin{array}{l}\text { Bohner and } \\
\text { Minner } \\
(2017)\end{array}$ & $\begin{array}{l}\text { Total expected } \\
\text { costs }\end{array}$ & MILP & $\begin{array}{l}\text { All-unit } \\
\text { quantity } \\
\text { discount, } \\
\text { Incremental } \\
\text { quantity } \\
\text { discount, } \\
\text { Business volume } \\
\text { discount }\end{array}$ & & * & MI & $\mathrm{NE}$ \\
\hline $\begin{array}{l}\text { Keshavarz } \\
\text { Ghorabaee } \\
\text { et al. (2017) }\end{array}$ & $\begin{array}{l}\text { Total positive } \\
\text { score of suppliers, } \\
\text { Total negative } \\
\text { score of suppliers, } \\
\text { Total purchasing } \\
\text { cost }\end{array}$ & $\begin{array}{l}\text { Type-2 fuzzy } \\
\text { sets, } \\
\text { EDAS, FMOP }\end{array}$ & & * & * & SI & $\mathrm{NE}$ \\
\hline
\end{tabular}


End of Table 1

\begin{tabular}{|c|c|c|c|c|c|c|c|}
\hline \multirow{2}{*}{ Authors } & \multirow{2}{*}{ Objectives } & \multirow{2}{*}{ Techniques } & \multirow{2}{*}{ Discount } & \multicolumn{3}{|c|}{$\begin{array}{c}\text { Model } \\
\text { Specifications }\end{array}$} & \multirow{2}{*}{$\mathrm{CS} / \mathrm{NE}$} \\
\hline & & & & SE & SOA & Item & \\
\hline $\begin{array}{l}\text { Cheragh- } \\
\text { alipour and } \\
\text { Farsad (2018) }\end{array}$ & $\begin{array}{l}\text { Total cost, Total } \\
\text { weighted scores of } \\
\text { suppliers }\end{array}$ & $\begin{array}{l}\text { Best worst } \\
\text { method, } \\
\text { MILP, Revised } \\
\text { multi- } \\
\text { choice goal } \\
\text { programming }\end{array}$ & $\begin{array}{l}\text { All-unit } \\
\text { quantity } \\
\text { discount, } \\
\text { Incremental } \\
\text { quantity } \\
\text { discount }\end{array}$ & $*$ & * & MI & CS \\
\hline $\begin{array}{l}\text { Mirzaee et al. } \\
\text { (2018) }\end{array}$ & $\begin{array}{l}\text { Total cost, Value } \\
\text { of purchasing }\end{array}$ & $\begin{array}{l}\text { MILP, } \\
\text { Preemptive } \\
\text { fuzzy goal } \\
\text { programming } \\
\text { model }\end{array}$ & $\begin{array}{l}\text { Incremental } \\
\text { quantity } \\
\text { discount }\end{array}$ & & * & MI & $\mathrm{NE}$ \\
\hline $\begin{array}{l}\text { Moheb- } \\
\text { Alizadeh and } \\
\text { Handfield } \\
(2019)\end{array}$ & $\begin{array}{l}\text { Cost, } \mathrm{CO}_{2} \\
\text { emission, Social } \\
\text { responsibility }\end{array}$ & $\begin{array}{l}\text { DEA, MILP, } \\
\varepsilon \text { - constraint } \\
\text { method }\end{array}$ & Price discount & * & * & MI & CS \\
\hline This paper & $\begin{array}{l}\text { Total purchasing } \\
\text { cost, Unqualified } \\
\text { auto-parts, } \\
\text { Delivery penalty }\end{array}$ & $\begin{array}{l}\text { DEA-TOPSIS- } \\
\text { FMIP, } \\
\text { Improved time } \\
\text { window }\end{array}$ & $\begin{array}{l}\text { All-unit } \\
\text { quantity } \\
\text { discounts }\end{array}$ & $*$ & * & SI & CS \\
\hline
\end{tabular}

Note: S - Suppliers evaluation; SOA - Supplier selection and order allocation; CS - Case study; NE Numerical example; MI - Multiple items; SI - Single item; SWOT - Strengths, weaknesses, opportunities and threats; EDAS - Evaluation based on distance from average solution.

\section{Supplier screening with the DEA-TOPSIS approach}

We adopt the DEA-TOPSIS approach to screen suppliers. Considering that potential suppliers provide different portfolios of components, each with heterogenous qualifications, we therefore group them by components, so as to evaluate the suppliers in a product-oriented setting, i.e., the proposed model will be applied for each component separately. The evaluation criteria include quality, service, technology and cost, and their scoring are determined by expert panels. Experts are selected from several departments of a company. For quality evaluation, experts are from the quality department. For service and cost evaluation, experts are from the procurement department. For technology evaluation, experts are from the technical department. Scoring is based on a predefined evaluation template.

The procedures of the approach are as follows:

Step 1. Define the input and output criteria for DEA cross-efficiency evaluation. The input criteria represent supplier capabilities and the output criteria represent supplier performance. The criteria of sensor components and engine components for the DEA approach are shown in Table 2 and Table 3 respectively. 
Table 2. Input and output criteria of suppliers for sensor components

\begin{tabular}{|l|l|}
\hline \multicolumn{1}{|c|}{ Inputs (supplier capabilities) } & \multicolumn{1}{c|}{ Outputs (supplier performance) } \\
\hline $\begin{array}{l}\text { Ability to complete production plan (S1) } \\
\text { Timely response in the supply chain (S2) }\end{array}$ & $\begin{array}{l}\text { Product development schedule (T2) } \\
\text { Technological advance (T3) }\end{array}$ \\
\hline Quality certification system (Q1) & On-time delivery and service (S3) \\
\hline Cost control ability (C1) & Price superiority (C2) \\
\hline Ability to exploit new products (T1) & Random inspection of products (Q3) \\
\hline Product rectification capability (Q2) & \\
\hline
\end{tabular}

Note: Q - quality; S - service; $\mathrm{T}$ - technology; C - cost.

Table 3. Input and output criteria of suppliers for engine components

\begin{tabular}{|l|l|}
\hline \multicolumn{1}{|c|}{ Inputs (supplier capabilities) } & \multicolumn{1}{c|}{ Outputs (supplier performance) } \\
\hline $\begin{array}{l}\text { Ability to complete production plan }\left(\mathrm{S} 1^{*}\right) \\
\text { Capacity flexibility }\left(\mathrm{S} 2^{*}\right) \\
\text { Ability to reach the ISO standards }\left(\mathrm{Q} 1^{*}\right)\end{array}$ & $\begin{array}{l}\text { After-sales claim in three months } \\
\left(\mathrm{Q} 3^{*}\right)\end{array}$ \\
\hline On-time delivery and service $\left(\mathrm{S} 3^{*}\right)$ \\
\hline Cost control ability $\left(\mathrm{C} 1^{*}\right)$ & Price superiority $\left(\mathrm{C} 2^{*}\right)$ \\
\hline $\begin{array}{l}\text { Ability to optimize products }\left(\mathrm{T} 1^{*}\right) \\
\text { Security and information system }\left(\mathrm{Q} 2^{*}\right)\end{array}$ & $\begin{array}{l}\text { Guarantee for after-sales }\left(\mathrm{S} 4^{*}\right) \\
\text { Contract execution cost }\left(\mathrm{C} 3^{*}\right)\end{array}$ \\
\hline
\end{tabular}

Note: Q - quality; S - service; $\mathrm{T}$ - technology; C - cost.

Step 2. Expert evaluation. Decision makers give the weights for all the criteria. Assume that $\Psi_{i}, i=1,2, \ldots, 6$ are the weights for the input criteria, $\delta_{j}, j=1,2, \ldots, 5$ are the weights for the output criteria. Experts score each of the criteria, and produce evaluation data at first. These include evaluations on the input variables $\kappa_{i}$, and that on the output variables $\kappa_{j}$, $\kappa_{i} \in\left[0, \Psi_{i}\right], \kappa_{j} \in\left[0, \delta_{j}\right]$.

Step 3. Transform original evaluation scores. To adapt the data for the DEA model formulations, we transform the evaluation data of input variables by using:

$$
\kappa_{i}^{\prime}=\Psi_{i}-\kappa_{i}(i=1,2, \ldots, 6) .
$$

In Eq. (1), $\kappa_{i}^{\prime}, i=1,2, \ldots, 6$ stand for the transformed data for inputs. In order to avoid zero value in the dominator of the DEA model, we set the data range as $[1,2]$. The input and output data are normalized by

$$
\begin{aligned}
& \alpha_{i}=\frac{\kappa_{i}^{\prime}-\kappa_{i}^{\min }}{\kappa_{i}^{\max }-\kappa_{i}^{\min ^{\prime}}}+1 \quad(i=1,2, \ldots, 6) ; \\
& \beta_{j}=\frac{\kappa_{j}-\kappa_{j}^{\min }}{\kappa_{j}^{\max }-\kappa_{j}^{\min }}+1 \quad(j=1,2, \ldots, 5) .
\end{aligned}
$$

In Eq. (2) and Eq. (3), $\kappa_{i}^{\min }$ and $\kappa_{i}^{\max }$ represent the minimum and maximum values for the transformed input data, $\kappa_{j}^{\min }$ and $\kappa_{j}^{\max }$ represent the minimum and maximum values accordingly for the original output data, $\alpha_{i}(i=1,2, \ldots, 6)$ stand for the normalized values of the input criteria, $\beta_{j}(j=1,2, \ldots, 5)$ stand for the normalized values of the output criteria. 
Step 4. Calculate the self-assessment efficiency value for each supplier (Charnes et al., 1978). The optimal self-assessment efficiency $E_{k k}{ }^{*}$ can be obtained by:

$$
\begin{aligned}
& \text { Maximize } E_{k k}=\sum_{y} O_{k y} v_{k y}
\end{aligned}
$$

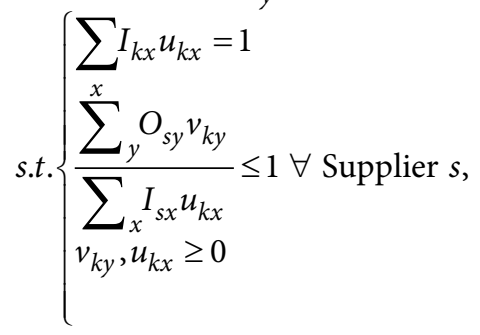

where $E_{k k}$ represents the relative productivity measure of the supplier $k$ from itself, $O_{k y}$ stands for the output $y$ of the supplier $k, O_{s y}$ stands for the output $y$ of the supplier $s, I_{s x}$ represents the input $x$ of the supplier $s, I_{k x}$ represents the input $x$ of the supplier $k, v_{k y}$ stands for the weight of the supplier $k$ for the output $y, u_{k x}$ stands for the weight of the supplier $k$ for the input $x$.

Step 5. Conduct cross-efficiency evaluation by using the model of Doyle and Green (1994), where $E_{k k}^{*}$ denotes the optimal self-assessment efficiency, $v_{k y}^{*}$ and $u_{k x}^{*}$ represent the optimal weights:

$$
\begin{aligned}
& \operatorname{Minimize} \sum_{y}\left(v_{k y} \sum_{s \neq k} O_{s y}\right)
\end{aligned}
$$

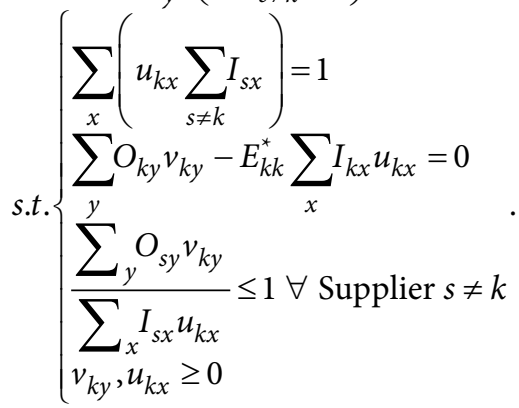

Based on $v_{k y}^{*}$ and $u_{k x}^{*}$ obtained by the model (5), the cross-efficiency $E_{k s}$ can be calculated by Eq. (6). The productivity measure of DEA (Doyle \& Green, 1994) is represented as follows:

$$
E_{k s}=\frac{\sum_{y} O_{s y} v_{k y}}{\sum_{x} I_{s x} u_{k x}},
$$

where $E_{k s}$ represents the relative productivity measure of the supplier $s$ from the supplier $k$.

Step 6. Obtain the cross-efficiency matrix (CEM) by using $E_{k k}^{*}(k=1,2, \ldots, n)$ as the diagonal elements and $E_{k s}(k, s=1,2, \ldots, n)$ as the other elements. Thus, we calculate the diversity performance $a_{k}(k=1,2, \ldots, n)$ and the comparative performance $e_{k}(k=1,2, \ldots, n)$ of CEM: 


$$
\begin{aligned}
& a_{k}=\frac{1}{n-1} \sum_{s \neq k} E_{k s}(k, s=1,2, \ldots, n) ; \\
& e_{k}=\frac{1}{n-1} \sum_{s \neq k} E_{s k}(k, s=1,2, \ldots, n),
\end{aligned}
$$

where $a_{k}$ represents the average efficiency values of the supplier $k$ rating the other suppliers; $e_{k}$ represents the average efficiency values of the supplier $k$ rated from the other suppliers.

Step 7. Assign weights for the two attributes $e_{k}$ and $a_{k}$ by decision makers. We set $w_{1}$ as the weight of $e_{k}, w_{2}$ as the weight of $a_{k}, \eta$ as a parameter controlling the component type. The values of $w_{1}$ and $w_{2}$ can be calculated by the following equations. Here, $r_{1}$ and $r_{2}$ are the weights for $e_{k}$ obtained from the decision makers.

$$
\begin{aligned}
& w_{1}=\left\{\begin{array}{l}
r_{1}, \text { if } \eta=1 \\
r_{2}, E \eta=2
\end{array} ;\right. \\
& w_{2}=1-w_{1} \text {. }
\end{aligned}
$$

In Eq. (9) and Eq. (10), if the component belongs to sensor, then $\eta$ is equal to 1; if the component belongs to engine, then $\eta$ is equal to 2 .

Step 8. Construct the weighted matrix $v$. To prepare the two-dimensional data yielded from the previous steps, and integrate them for ranking suppliers with the TOPSIS method, we build and normalize the weighted matrix $v$ as below:

$$
v=\left[\begin{array}{ccc}
w_{1} \frac{e_{1}}{\sqrt{\sum_{k=1}^{n} e_{k}^{2}}} & w_{2} \frac{a_{1}}{\sqrt{\sum_{k=1}^{n} a_{k}^{2}}} \\
w_{1} \frac{e_{2}}{\sqrt{\sum_{k=1}^{n} e_{k}^{2}}} & w_{2} \frac{a_{2}}{\sqrt{\sum_{k=1}^{n} a_{k}^{2}}} \\
w_{1} \frac{e_{n}}{\sqrt{\sum_{k=1}^{n} e_{k}^{2}}} & w_{2} \frac{a_{n}}{\sqrt{\sum_{k=1}^{n} a_{k}^{2}}}
\end{array}\right] .
$$

Step 9. Construct ideal solutions. According to Talluri, Decampos, and Hult (2013), $e_{k}$ is a benefit attribute and $a_{k}$ is a cost attribute. Therefore, we adopt the following equations to construct the optimal ideal solution $v_{j}^{+}$and the negative ideal solution $v_{j}^{-}$regarding the two performance dimensions:

$$
\begin{aligned}
& v_{j}^{+}=\lambda \max _{i}\left\{v_{i j}\right\}+(1-\lambda) \min _{i}\left\{v_{i j}\right\} ; \\
& v_{j}^{-}=\lambda \min _{i}\left\{v_{i j}\right\}+(1-\lambda) \max _{i}\left\{v_{i j}\right\},
\end{aligned}
$$

where $\lambda$ is used to control the type of the attribute, we set $\lambda$ to 1 for the attribute $e_{k}$ and set $\lambda$ to 0 for the attribute $a_{k}$. 
Step 10. Calculate the overall performance for each supplier according to their relative distances to the ideal solutions. The larger the overall performance is, the better the supplier is preferred:

$$
c_{i}^{*}=\frac{\sqrt{\sum_{j=1}^{2}\left(v_{i j}-v_{j}^{-}\right)^{2}}}{\sqrt{\sum_{j=1}^{2}\left(v_{i j}-v_{j}^{+}\right)^{2}}+\sqrt{\sum_{j=1}^{2}\left(v_{i j}-v_{j}^{-}\right)^{2}}} \quad(i=1,2, \ldots, n) .
$$

\section{Allocating orders by a FMIP model with multiple objectives under all-unit quantity discount}

According to the evaluation result obtained in Section 3, we select the top M suppliers as candidates for each automobile component. The subsequent procedures are designed to search for optimal order allocations among these screened candidate suppliers for each component respectively. Total cost, quality and delivery are selected as the optimized objectives for establishing the model, and demand constraints, capacity constraints and delivery time constraints are considered in the model. Decision makers define the upper limit number of selected suppliers for the order allocations and the weights for the objectives and constraints for each component. As the discount policy and delivery penalty are involved, we build a fuzzy mixed integer programming (FMIP) model with multiple objectives, all-unit quantity discount piecewise function as well as an improved soft time-window to find optimal order allocations. The decision variables and parameters of the model are given as follows:

\section{Decision variables:}

$X_{j}$ - Orders distributed to supplier $j$.

$Y_{j}-0-1$ variable determined by whether a component is supplied by supplier $j$ ( $j=1$ if supplied; $j=0$ if not supplied).

\section{Parameters:}

$A_{j}$ - All-unit quantity discount coefficient provided by supplier $j$.

$C_{j}$ - Unit variable cost of a component provided by supplier $j$.

$A c_{j}$ - Variable cost of a component provided by supplier $j$ under all-unit quantity discount.

$F_{j}$ - Fixed cost if purchased from supplier $j$.

$q_{j}$ - Defect rate of the component provided by supplier $j$.

$p_{j}$ - Unit penalty if a component provided by supplier $j$ is not delivered on time.

$l_{j}$ - Lead time for a component delivered by supplier $j$.

$V$ - Earliest delivery date (EDD).

$L$ - Latest delivery date (LDD).

$L V$ - Lower bound for the EDD.

$U L$ - Upper bound for the LDD. 
$P V$ - Penalty rate if delivery time is between $L V$ and $V$.

$P L$ - Penalty rate if delivery time is between $L$ and $U L$.

$P l$ - Penalty rate if delivery time is before $L V$.

$P h$ - Penalty rate if delivery time is after $U L$.

$C a_{j}$ - Capacity of supplier $j$.

$\operatorname{Min}_{j}$ The minimum order quantities if purchased from supplier $j$.

$D$ - Demand of the component.

$m$ - Number of candidate suppliers.

$W$ - Upper limit of selected suppliers.

Firstly, we formulate a segmented all-unit quantity discount function shown as follows:

$$
A_{j}=\left\{\begin{array}{ll}
U_{j} & \text { if } X_{j} \geq J_{j} \\
T_{j} & \text { if } J_{j} \geq X_{j} \geq H_{j} \\
M_{j} & \text { if } H_{j} \geq X_{j} \geq G_{j} \\
0 & \text { if } G_{j} \geq X_{j}
\end{array},\right.
$$

where $j=1,2, \ldots, m$. In the all-unit quantity discount, buyers get a discount for every component when purchase quantity equals or exceeds the thresholds $G_{j}, H_{j}, J_{j}$ predefined in the discount policy. In the definition, the closer $A_{j}$ is to zero, the smaller the discount is. Thus, a component gets the discounted price $\left(1-A_{j}\right) \times C_{j}$ where $A_{j}$ varies with the purchase quantity intervals $\left[H_{j}, G_{j}\right],\left[J_{j}, H_{j}\right],\left[J_{j},+\infty\right]$. With the incremental quantity discount policy, buyers get a discount for extra components only for the purchase quantity that exceeds the thresholds, the coefficient $A_{j}$ under this policy doesn't vary with excess quantity or quantity range.

Here we define four discount segments: (i) If purchase quantity is lower than $G_{j}$, then there is no discount provided; (ii) If purchase quantity is greater than $J_{j}$, then the discount coefficient is equal to $U_{j}$; (iii) If purchase quantity is between $J_{j}$ and $H_{j}$, then the discount coefficient is $T_{j}$; (iv) If purchase quantity is between $H_{j}$ and $G_{j}$, then the discount coefficient is $M_{j}$. Here, $U_{j}, T_{j}$ and $M_{j}$ vary from zero to one.

Given the all-unit discount policy enacted, let $A c_{j}$ be the discounted cost of a component provided by supplier $j$, which can be expressed as below:

$$
A c_{j}=\left(1-A_{j}\right) \times C_{j} \times X_{j},
$$

where, $A c_{j}$ will be eventually applied in the computation of total cost for component.

As cost, delivery time, demand and production capacity may be uncertain, a fuzzy mixed integer programming model (FMIP) for each component with multiple objectives is formulated, where $f_{1}$ represents the total cost, and $f_{2}$ represents the unqualified items in terms of product quality, $f_{3}$ denotes the penalty caused by the delivery schedule violation; they each are the summation on all selected suppliers. Thus, the FMIP model is formulated as follows:

$$
\begin{aligned}
& \operatorname{Min} f_{1}(X, Y) \cong \sum_{j=1}^{m} A c_{j}+\sum_{j=1}^{m} F_{j} Y_{j} ; \\
& \operatorname{Min} f_{2}(X) \cong \sum_{j=1}^{m} X_{j} q_{j} ;
\end{aligned}
$$




$$
\begin{array}{ll} 
& \operatorname{Min}_{3}(X) \cong \sum_{j=1}^{m} X_{j} p_{j} \\
\text { s.t. } & \sum_{j=1}^{m} X_{j}\left(1-q_{j}\right) \tilde{\geq} D ; \\
& X_{j} \leq Y_{j} C a_{j}, \forall j ; \\
& X_{j} \geq Y_{j} \operatorname{Min}_{j}, \forall j ; \\
& \sum_{j=1}^{m} Y_{j} \leq W ; \\
& Y_{j} \in\{0,1\}, \forall j ; \\
& X_{j} \geq 0, \forall j,
\end{array}
$$

where Eq. (17) defines the cost objective function, and the item $\sum_{j=1}^{m} A c_{j}$ describes the total variable cost under all-unit discount policy, while $\sum_{j=1}^{m} F_{j} Y_{j}$ stands for the total fixed cost. Eq. (18) defines the quality objective function that minimizes the total defect items and Eq. (19) defines the delivery objective function that minimizes the total unpunctual delivery penalty.

For the constraints in the model, constraint (20) requires that the quantity of qualified components purchased from selected suppliers should meet the demand. Constraint (21) restricts the allocated quantity of components for supplier $j$ not to exceed its capacity. Constraint (22) provides the minimum order quantity of components if purchased from the supplier $j$. Constraint (23) enforces the upper limit number of selected suppliers. Constraint (24) defines the binary characteristic of the decision variables. Constraint (25) sets the purchasing quantity as a positive integer.

As the suppliers of automotive components are inherently heterogenous, not only in the aspects to be evaluated, but also in their offering of product portfolios. Yu and Lin (2012) have developed a model that computes the procurement proposal once for all products, by assuming the suppliers provide the same product portfolio, but this is the not case with our automotive component procurement. In such an application scene, we design the model setting as such, that the model is implemented in parallel independently for each component using the idiosyncratic product-oriented information, which is well in match with the actual data generating process of a company. The procurer assumes product-oriented procurement decision making, no bundling sales are allowed. The optimization model runs for each item independently for the multiple components procurement case, as procurer evaluates the supply performance of component-item independently.

If the automobile components are delivered beyond permitted time, the supplier should pay penalties. Here we improve the soft time-window mechanism defined by Ioannou, Kritikos, and Prastacos (2003) as follows: 


$$
p_{j}=\left\{\begin{array}{ll}
C_{j} P l\left(L V-l_{j}\right) & \text { if } l_{j}<L V \\
C_{j} P V\left(V-l_{j}\right) & \text { if } L V \leq l_{j} \leq V \\
0 & \text { if } V \leq l_{j} \leq L \\
C_{j} P L\left(l_{j}-L\right) & \text { if } L \leq l_{j} \leq U L \\
C_{j} P h\left(l_{j}-U L\right) & \text { if } U L<l_{j}
\end{array} .\right.
$$

In Eq. (26), $p_{j}$ represents unit penalty for non-on-time delivery for component. With the penalty rate given by buyers, we build up a linear relationship between the unit penalty and the unit variable cost. In order to avoid interruption of product line caused by non-on-time delivery, we use high penalty instead of rejecting components (Yu \& Lin, 2012) when delivery time is before the lower bound for the EDD or after the upper bound for the LDD. The improved soft time-window mechanism is shown in Figure 1. If the component is delivered in the time period of $L V$ and $V$ or the time period of $L$ and $U L$, suppliers should pay low penalties. The suppliers will pay no penalty only if the component is delivered within $V$ and $L$.

Drawing upon the algorithm of Yu and Lin (2012), we propose an interactive algorithm to solve the FMIP model (See Figure 2). Assume that there are $P$ objectives and $Q$ demand constraints. The steps of the algorithm are as follows:

Step 1. Use the triangular membership functions and the centroid method to defuzzicate the fuzzy capacity, fuzzy delivery time and fuzzy demand.

Step 2. For each of the objective functions $f_{l}(l=1,2, \ldots, P)$, calculate the lower bound $f_{l}^{-}(l=1,2, \ldots, P)$ and the upper bound $f_{l}^{+}(l=1,2, \ldots, P)$ separately by using the max-min approach (Zimmermann, 1978). Then obtain the pessimistic value $D_{k}^{-}(k=1,2, \ldots, Q)$, the probable value $\overline{D_{k}}(k=1,2, \ldots, Q)$ and the optimistic value $D_{k}^{+}(k=1,2, \ldots, Q)$ from decision makers for the demand.

Step 3. Build membership functions respectively for all objective functions and fuzzy demand constraints. The membership function $R\left(f_{l}(x)\right)(l=1,2, \ldots, P)$ for fuzzy objective functions and the membership function $R\left(D_{k}(x)\right)(k=1,2, \ldots, Q)$ for fuzzy demand constraints are given below:

Due to that the three objectives are all minimization goals, the linear membership function for the fuzzy objectives is given as follows:

$$
\begin{aligned}
& R\left(f_{l}(x)\right)=\left\{\begin{array}{cl}
1 & \text { if } f_{l}(x) \leq f_{l}^{-} \\
\frac{f_{l}^{+}-f_{l}(x)}{f_{l}^{+}-f_{l}^{-}} & \text {if } f_{l}^{-} \leq f_{l}(x) \leq f_{l}^{+}, l=1,2, \ldots, P . \\
0 & \text { if } f_{l}(x) \geq f_{l}^{+}
\end{array}\right. \\
& \underset{L V}{\text { High penalty }} \begin{array}{c}
\text { Low } \\
\text { penalty }
\end{array} \begin{array}{c}
\text { No } \\
\text { penalty }
\end{array}
\end{aligned}
$$

Figure 1. Soft time-window with non-on-time delivery penalties

Note: $L V$ - Lower bound for the earliest delivery date; $V$ - Earliest delivery date;

$L$ - Latest delivery date; $U L$ - Upper bound for latest delivery date. 


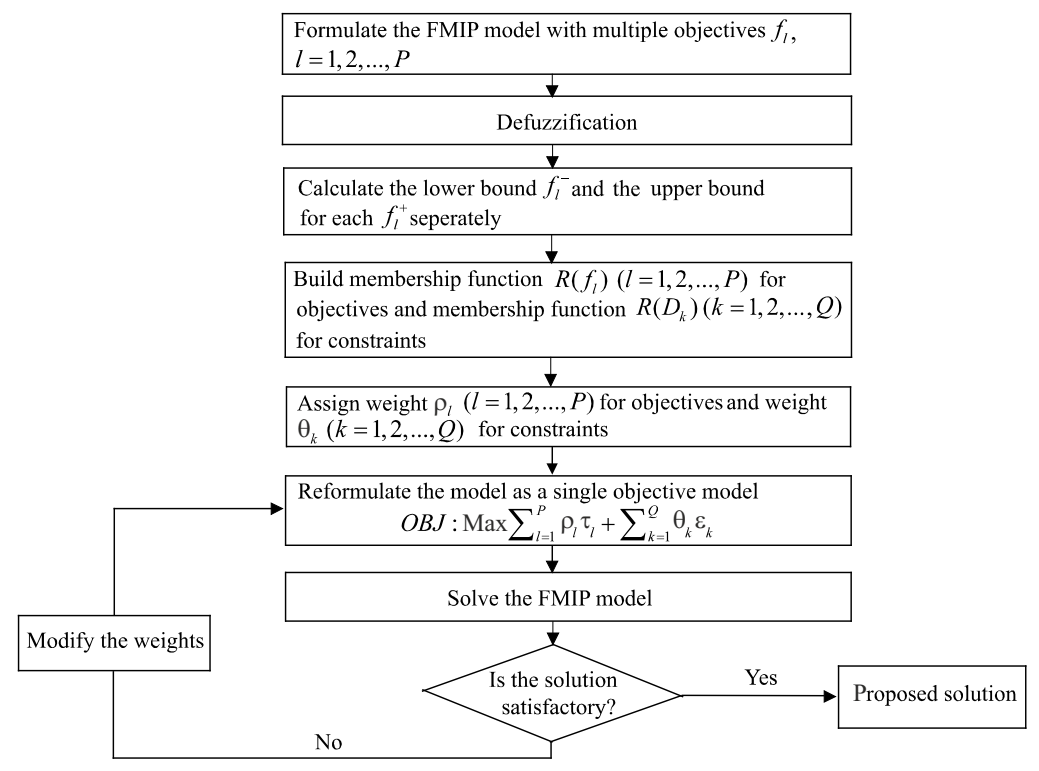

Figure 2. Interactive algorithm of the FMIP model

Note: $\tau_{l}, l=1,2, \ldots, P$ : the achievement levels for objective functions;

$\varepsilon_{k}, k=1,2, \ldots, Q$ : the achievement levels for constraints.

The linear membership function for the fuzzy demand constraint is given as follows:

$$
R\left(D_{k}(x)\right)=\left\{\begin{array}{cl}
\frac{D_{k}(x)-D_{k}^{-}}{\overline{D_{k}}-D_{k}^{-}} & \text {if } D_{k}^{-}<D_{k}(x) \leq \overline{D_{k}} \\
\frac{D_{k}^{+}-D_{k}(x)}{D_{k}^{+}-\overline{D_{k}}} & \text { if } \overline{D_{k}} \leq D_{k}(x)<D_{k}^{+} \\
0 & \text { if } D_{k}(x) \leq D_{k}^{-} \text {or } D_{k}(x) \geq D_{k}^{+}
\end{array}, \quad k=1,2, \ldots, Q .\right.
$$

Step 4. Assign weight $\rho_{l}(l=1,2, \ldots, P)$ for the objectives and weight $\theta_{k}(k=1,2, \ldots, Q)$ for the demand constraints from decision makers.

Step 5. Reformulate the model as a single objective model by aggregating the weighted achievement level (Amid et al., 2006). In formula (29), $\tau_{l}(l=1,2, \ldots, P)$ stands for the achievement level for the objective and $\varepsilon_{k}(k=1,2, \ldots, Q)$ stands for the achievement level for the demand constraint.

$$
\operatorname{Max} \sum_{l=1}^{l=P} \rho_{l} \tau_{l}+\sum_{k=1}^{k=Q} \theta_{k} \varepsilon_{k}
$$

s.t.

$$
\begin{aligned}
\tau_{l} & \leq R\left(f_{l}(x)\right), l=1,2, \ldots, P ; \\
\varepsilon_{k} & \leq R\left(D_{k}(x)\right), k=1,2, \ldots, Q ;
\end{aligned}
$$




$$
\begin{aligned}
& \tau_{l}, \varepsilon_{k} \in[0,1], l=1,2, \ldots, P ; k=1,2, \ldots, Q ; \\
& \sum_{l=1}^{P} \rho_{l}+\sum_{k=1}^{Q} \theta_{k}=1, \rho_{l}, \theta_{k} \geq 0
\end{aligned}
$$

Step 6. Find the optimal solution for the single objective model.

Step 7. Judge whether the solution is acceptable for decision makers or not. If not acceptable, go to step 4; If acceptable, then a proposed solution is obtained.

\section{Case study: multiple automobile components procurement using an iterative single-item FMIP model}

In this section, we apply the approach in the case of Chongqing SOKON Industry Group Stock Corporation Ltd in China. The purchasing department needs to purchase four components including "intake air pressure sensor", "oil injection nozzle", "oxygen sensor" and "crankshaft" from plenty of potential suppliers. Oil injection nozzle and crankshaft are engine components, intake air pressure sensor and oxygen sensor are sensor components. There are thirty potential suppliers in the current supplier base providing the above four automobile components. The potential suppliers and the components they produce are listed in Table 4. Decision makers of the company want to select candidates from the company's supplier base and find optimal order allocations for each of the four components.

Table 4. Potential suppliers and produced components

\begin{tabular}{|c|c|c|c|c|c|c|c|c|c|}
\hline Supplier & \multicolumn{4}{|c|}{ Component } & Supplier & \multicolumn{4}{|c|}{ Component } \\
\hline 1 & A & B & & D & 16 & A & & & D \\
\hline 2 & A & & C & & 17 & & B & C & \\
\hline 3 & A & & & D & 18 & A & & C & D \\
\hline 4 & A & B & C & & 19 & A & B & & \\
\hline 5 & & B & & D & 20 & & B & & D \\
\hline 6 & A & & C & & 21 & A & B & C & \\
\hline 7 & A & B & C & D & 22 & & B & & D \\
\hline 8 & & B & C & & 23 & A & & C & D \\
\hline 9 & A & & C & D & 24 & A & B & & \\
\hline 10 & & B & & D & 25 & & B & C & D \\
\hline 11 & A & B & C & & 26 & A & & C & \\
\hline 12 & & B & C & D & 27 & & B & & D \\
\hline 13 & A & & & & 28 & A & B & C & \\
\hline 14 & & B & C & D & 29 & & B & C & D \\
\hline 15 & & B & C & & 30 & A & & C & \\
\hline
\end{tabular}

Note: A - intake air pressure sensor; B - oil injection nozzle; C - oxygen sensor; D - crankshaft. 
In the rapidly-changing market, the demand for each component is hard to be precisely determined in some circumstances. In this case, the fuzzy demand is expressed as "pessimistic", "most likely" or "optimistic". The purchasing manager forecasts the demand for the four components A to D, and assigns the values of triangular demand for them that are A (1800, $2100,2350), B(2250,2450,2600), C(1700,2050,2000)$, and D $(2400,2550,2750)$ respectively. The demand for each component should be satisfied and the actual purchase quantity should be in principle greater than the demand.

In this case, the purchase manager wishes to select no more than two suppliers from candidates to allocate orders for each component. If buyers choose a supplier, the orders should be greater than the threshold value $\mathrm{Min}_{j}$ and less than the capacity $\mathrm{Ca}_{j}$. The company's decision makers choose three objectives including total cost, quality and delivery time and also consider uncertainty factors. In order to reduce total cost and realize sales promotion, all the suppliers provide all-unit quantity discount. The components are required to be delivered in a permitted time range. If delivery time is out of the range, suppliers should pay delay penalties. Table 5 gives the best delivery time, time window and penalty rate. Considering that engine components play a more important role in automobile manufacturing, its penalty rate are accordingly higher than that of sensor components.

Table 5. Lead time, time window and penalty rate

\begin{tabular}{|l|c|c|c|c|c|c|c|c|c|}
\hline & \multirow{2}{*}{$\begin{array}{c}\text { Best delivery } \\
\text { time (day) }\end{array}$} & \multicolumn{4}{|c|}{ Time window(day) } & \multicolumn{4}{c|}{ Penalty rate } \\
\cline { 3 - 11 } & & VL & V & L & UL & PV & PL & Pl & Ph \\
\hline Sensor component & 6 & 3 & 5 & 7 & 10 & $10 \%$ & $20 \%$ & $30 \%$ & $40 \%$ \\
\hline Engine component & 6.5 & 4 & 6 & 7 & 8 & $20 \%$ & $30 \%$ & $35 \%$ & $45 \%$ \\
\hline
\end{tabular}

\subsection{Supplier screening and ranking}

Potential suppliers are divided into four groups for each component. Then, the criteria weights are obtained for the engine components and sensor components respectively. Table 6 and Table 7 show the weights and evaluation standards of sub-criterion for the two types of components. Based on these evaluation standards, experts give the original evaluation scores that are shown in the Appendix (Tables 22-25). Potential suppliers will be evaluated for each month, thus, the evaluation scores in this paper are valid only for current month.

Table 6. Weights and evaluation criteria for sensor components

\begin{tabular}{|c|l|c|l|}
\hline Criteria & \multicolumn{1}{|c|}{ Sub-criteria } & Weights & \multicolumn{1}{c|}{ Details of evaluation } \\
\hline Quality & $\begin{array}{l}\text { Quality certification } \\
\text { system (Q1) }\end{array}$ & 15 & $\begin{array}{l}\text { 1. Percentage of qualified sensor components in previous } \\
\text { month } \\
\text { 2. Whether TS16949 passed } \\
\text { 3. Whether ISO9001 passed } \\
\text { 4. The quality can meet the production line requirements } \\
\text { 5. Avoid on-line selection or returning for renovation }\end{array}$ \\
\hline
\end{tabular}


End of Table 6

\begin{tabular}{|c|c|c|c|}
\hline Criteria & Sub-criteria & Weights & Details of evaluation \\
\hline \multirow[t]{2}{*}{ Quality } & $\begin{array}{l}\text { Component } \\
\text { rectification } \\
\text { capability (Q2) }\end{array}$ & 10 & $\begin{array}{l}\text { 1.The same quality problem recurred less than twice in } \\
\text { previous month } \\
\text { 2. The rectification is carried out within allowable time } \\
\text { 3. Solve quality problems within allowable time } \\
\text { 4. Avoid being required to stop supply }\end{array}$ \\
\hline & $\begin{array}{l}\text { Components random } \\
\text { inspection (Q3) }\end{array}$ & 15 & $\begin{array}{l}\text { 1. Percentage of qualified components from random } \\
\text { inspection } \\
\text { 2. Variation of percentage of qualified components from } \\
\text { random inspection compared with previous month }\end{array}$ \\
\hline \multirow{3}{*}{ Service } & $\begin{array}{l}\text { Ability to complete } \\
\text { production plan }(\mathrm{S} 1)\end{array}$ & 10 & $\begin{array}{l}\text { 1. Arrival rate of components } \\
\text { 2. Variation of arrival rate of components compared with } \\
\text { last month }\end{array}$ \\
\hline & $\begin{array}{l}\text { Timely response in } \\
\text { the supply chain (S2) }\end{array}$ & 5 & $\begin{array}{l}\text { 1. Give a reply on time } \\
\text { 2. Whether the reply meets requirements }\end{array}$ \\
\hline & $\begin{array}{l}\text { On-time delivery and } \\
\text { service (S3) }\end{array}$ & 5 & $\begin{array}{l}\text { 1.Return unqualified components in time } \\
\text { 2.Deliver components within allowable time }\end{array}$ \\
\hline \multirow{3}{*}{$\begin{array}{l}\text { Tech- } \\
\text { nology }\end{array}$} & $\begin{array}{l}\text { Ability to exploit new } \\
\text { components (T1) }\end{array}$ & 10 & $\begin{array}{l}\text { 1. Quality of samples of new components } \\
\text { 2. Whether new components are accompanied by } \\
\text { technical documents }\end{array}$ \\
\hline & \begin{tabular}{|l|} 
Component \\
development \\
schedule (T2) \\
\end{tabular} & 10 & $\begin{array}{l}\text { 1. Avoid delay of component development } \\
\text { 2. Avoid delay of component modification }\end{array}$ \\
\hline & $\begin{array}{l}\text { Technological } \\
\text { advance (T3) }\end{array}$ & 5 & $\begin{array}{l}\text { 1. Whether a quality technology promotion plan is put } \\
\text { forward } \\
\text { 2. Whether a cost reduction and technology upgrading } \\
\text { plan is put forward } \\
\text { 3. Implementation of technical plans }\end{array}$ \\
\hline \multirow{2}{*}{ Cost } & $\begin{array}{l}\text { Cost control ability } \\
\text { (C1) }\end{array}$ & 10 & $\begin{array}{l}\text { 1. Variation of cost control rate } \\
\text { 2. Cost control rate less than } 70 \%\end{array}$ \\
\hline & $\begin{array}{l}\text { Price superiority } \\
\text { (C2) }\end{array}$ & 5 & 1. Differential price of the same sensor components \\
\hline
\end{tabular}

Table 7. Weights and evaluation criteria for engine components

\begin{tabular}{|c|l|c|l|}
\hline Criteria & \multicolumn{1}{|c|}{ Sub-criteria } & Weights & \multicolumn{1}{c|}{ Details of evaluation } \\
\hline Quality & $\begin{array}{l}\text { Ability to reach the } \\
\text { ISO standards (Q1*) }\end{array}$ & 10 & $\begin{array}{l}\text { 1. Whether TS16949 passed } \\
\text { 2. Whether ISO9001 passed } \\
\text { 3. Percentage of qualified engine components in previous } \\
\text { month }\end{array}$ \\
\cline { 2 - 4 } & $\begin{array}{l}\text { Security and } \\
\text { information system }\end{array}$ & 15 & $\begin{array}{l}\text { 1. Avoid unqualified products caused by quality defects } \\
\text { of engine components } \\
\text { 2. Avoid production line interruption caused by quality } \\
\text { defects } \\
\text { 3. Avoid security incidents }\end{array}$ \\
\cline { 2 - 4 } & $\begin{array}{l}\text { After-sales claim in } \\
\text { three months (Q3*) }\end{array}$ & 15 & $\begin{array}{l}\text { 1. Quality assurance within three months } \\
\text { 2. Unqualified components in three months is less than } \\
\text { the quantity allowed }\end{array}$ \\
\hline
\end{tabular}


End of Table 6

\begin{tabular}{|c|c|c|c|}
\hline Criteria & Sub-criteria & Weights & Details of evaluation \\
\hline \multirow{4}{*}{ Service } & $\begin{array}{l}\text { Ability to complete } \\
\text { production plan } \\
\left(\mathrm{S} 1^{\star}\right)\end{array}$ & 10 & $\begin{array}{l}\text { 1. Arrival rate of components } \\
\text { 2. Variation of arrival rate of components compared with } \\
\text { previous month }\end{array}$ \\
\hline & $\begin{array}{l}\text { Capacity flexibility } \\
\left(\mathrm{S} 2^{\star}\right)\end{array}$ & 5 & 1. Delivery capacity more is than 100 units at one time \\
\hline & $\begin{array}{l}\text { Deliver and serve on } \\
\text { time }\left(\mathrm{S}^{*}\right)\end{array}$ & 5 & $\begin{array}{l}\text { 1. Deliver components within allowable time } \\
\text { 2. Give a reply on time }\end{array}$ \\
\hline & $\begin{array}{l}\text { Guarantee for after- } \\
\text { sales }\left(S 4^{\star}\right)\end{array}$ & 5 & Warranty for components in three months \\
\hline $\begin{array}{l}\text { Tech- } \\
\text { nology }\end{array}$ & $\begin{array}{l}\text { Ability for product } \\
\text { optimization }\left(\mathrm{T} 1^{\star}\right)\end{array}$ & 15 & $\begin{array}{l}\text { 1. Carry out technical optimization programs } \\
\text { 2. Implement technical programs }\end{array}$ \\
\hline \multirow{3}{*}{ Cost } & $\begin{array}{l}\text { Cost control ability } \\
\left(\mathrm{C} 1^{\star}\right)\end{array}$ & 10 & $\begin{array}{l}\text { 1. Variation of cost control rate } \\
\text { 2. Cost control rate less than } 65 \%\end{array}$ \\
\hline & $\begin{array}{l}\text { Price superiority } \\
\text { (C2) }\end{array}$ & 5 & 1. Differential price of the same engine components \\
\hline & $\begin{array}{l}\text { Contract execution } \\
\text { cost }\left(\mathrm{C}^{*}\right)\end{array}$ & 5 & $\begin{array}{l}\text { 1.Whether procurement contracts are implemented } \\
\text { 2. Whether there is any breach of procurement contracts }\end{array}$ \\
\hline
\end{tabular}

Next, we transform input scores and normalize these transformed data by using formulas (1)-(3) mentioned in Section 3, and then we obtain processed data for the four components that are shown in Table 8 to Table 11.

Table 8. Processed data of intake air pressure sensor for the DEA approach

\begin{tabular}{|c|c|c|c|c|c|c|c|c|c|c|c|}
\hline \multirow{2}{*}{ Supplier } & \multicolumn{7}{|c|}{ Input } & \multicolumn{6}{|c|}{ Output } \\
\cline { 2 - 14 } & S1 & S2 & Q1 & C1 & T1 & Q2 & T3 & T2 & S3 & C2 & Q3 \\
\hline 1 & 1.5 & 1.1 & 1.0 & 1.9 & 1.0 & 1.2 & 1.8 & 1.7 & 2.0 & 2.0 & 2.0 \\
\hline 2 & 1.4 & 1.3 & 1.4 & 1.8 & 1.3 & 1.0 & 1.9 & 1.7 & 1.9 & 1.5 & 1.3 \\
\hline 3 & 2.0 & 1.7 & 1.1 & 1.9 & 1.5 & 1.9 & 1.3 & 1.4 & 2.0 & 1.7 & 1.6 \\
\hline 4 & 1.0 & 2.0 & 1.3 & 1.0 & 1.3 & 1.1 & 1.5 & 2.0 & 2.0 & 2.0 & 1.8 \\
\hline 6 & 1.5 & 1.0 & 1.2 & 1.8 & 1.6 & 1.1 & 1.0 & 1.3 & 1.2 & 1.3 & 1.2 \\
\hline 7 & 1.0 & 1.1 & 1.1 & 1.2 & 1.2 & 1.3 & 1.8 & 1.2 & 1.5 & 1.6 & 1.9 \\
\hline 9 & 1.4 & 1.3 & 1.3 & 1.9 & 1.7 & 1.9 & 1.3 & 1.7 & 2.0 & 1.9 & 1.0 \\
\hline 11 & 1.2 & 1.0 & 1.4 & 1.8 & 1.2 & 1.1 & 2.0 & 2.0 & 1.8 & 1.0 & 1.7 \\
\hline 13 & 1.4 & 1.2 & 1.1 & 2.0 & 1.1 & 1.3 & 1.7 & 1.4 & 1.0 & 1.6 & 1.4 \\
\hline 16 & 1.6 & 1.0 & 1.4 & 1.7 & 2.0 & 2.0 & 1.9 & 1.2 & 1.1 & 1.5 & 1.4 \\
\hline 18 & 1.9 & 1.1 & 1.0 & 1.8 & 1.1 & 1.1 & 1.8 & 1.6 & 1.4 & 1.4 & 2.0 \\
\hline 19 & 1.3 & 1.7 & 1.0 & 1.7 & 1.0 & 1.9 & 1.1 & 1.8 & 1.2 & 1.3 & 1.4 \\
\hline 21 & 1.6 & 1.0 & 1.3 & 1.5 & 2.0 & 1.1 & 1.8 & 1.1 & 1.4 & 2.0 & 1.5 \\
\hline 23 & 1.8 & 1.8 & 1.0 & 1.8 & 1.0 & 1.6 & 1.5 & 1.4 & 1.8 & 1.6 & 1.8 \\
\hline 24 & 1.4 & 1.0 & 1.1 & 1.8 & 1.4 & 1.7 & 1.9 & 1.0 & 1.4 & 1.7 & 1.2 \\
\hline 26 & 1.2 & 1.7 & 1.2 & 1.9 & 1.2 & 1.3 & 1.7 & 1.4 & 2.0 & 1.8 & 1.2 \\
\hline 28 & 1.1 & 1.3 & 1.1 & 1.5 & 1.2 & 1.4 & 1.6 & 1.3 & 1.7 & 1.8 & 1.5 \\
\hline 30 & 1.0 & 1.8 & 2.0 & 1.3 & 1.6 & 1.6 & 1.2 & 1.3 & 1.6 & 1.8 & 1.9 \\
\hline
\end{tabular}


Table 9. Processed data of oil injection nozzle for the DEA approach

\begin{tabular}{|c|c|c|c|c|c|c|c|c|c|c|c|}
\hline \multirow{2}{*}{ Supplier } & \multicolumn{7}{|c|}{ Input } & \multicolumn{5}{|c|}{ Output } \\
\cline { 2 - 13 } & S1 $^{*}$ & S2 $^{*}$ & Q1 $^{*}$ & C1 $^{*}$ & T1 $^{*}$ & Q2 $^{*}$ & Q3 $^{*}$ & S3 $^{*}$ & C2 $^{*}$ & S4 $^{*}$ & C3 $^{*}$ \\
\hline 1 & 1.5 & 1.1 & 1.2 & 1.7 & 1.5 & 1.1 & 1.5 & 1.9 & 1.9 & 1.8 & 1.9 \\
\hline 4 & 1.0 & 1.3 & 1.5 & 1.0 & 2.0 & 1.1 & 1.6 & 2.0 & 2.0 & 1.7 & 1.8 \\
\hline 5 & 1.5 & 1.7 & 1.4 & 1.7 & 1.6 & 1.1 & 2.0 & 1.4 & 1.9 & 1.8 & 1.3 \\
\hline 7 & 1.1 & 1.2 & 1.2 & 1.1 & 1.5 & 1.0 & 1.6 & 1.4 & 1.7 & 1.5 & 1.9 \\
\hline 8 & 2.0 & 1.0 & 1.5 & 1.6 & 1.3 & 2.0 & 1.1 & 1.5 & 1.8 & 1.7 & 1.4 \\
\hline 10 & 1.4 & 1.1 & 1.7 & 1.5 & 1.2 & 1.0 & 2.0 & 1.1 & 1.6 & 1.5 & 2.0 \\
\hline 11 & 1.2 & 1.6 & 1.5 & 1.5 & 1.5 & 1.0 & 1.0 & 1.8 & 1.0 & 1.0 & 1.6 \\
\hline 12 & 1.5 & 1.9 & 1.6 & 1.8 & 1.9 & 1.4 & 1.5 & 1.3 & 1.4 & 1.9 & 1.7 \\
\hline 14 & 1.6 & 1.1 & 1.3 & 1.2 & 1.4 & 1.4 & 1.4 & 1.1 & 1.3 & 1.8 & 1.4 \\
\hline 15 & 1.4 & 1.5 & 1.3 & 1.6 & 1.7 & 1.2 & 1.7 & 1.5 & 1.8 & 1.5 & 1.3 \\
\hline 17 & 1.8 & 2.0 & 1.5 & 1.7 & 1.8 & 1.7 & 1.5 & 1.1 & 1.3 & 1.4 & 1.4 \\
\hline 19 & 1.3 & 1.7 & 1.0 & 1.5 & 1.5 & 1.0 & 1.9 & 1.1 & 1.3 & 1.6 & 1.8 \\
\hline 20 & 1.4 & 1.1 & 1.0 & 1.5 & 1.0 & 1.1 & 1.9 & 1.7 & 1.3 & 1.7 & 1.1 \\
\hline 21 & 1.6 & 1.1 & 1.8 & 1.4 & 1.3 & 1.2 & 1.8 & 1.3 & 2.0 & 1.7 & 1.2 \\
\hline 22 & 1.6 & 1.3 & 1.5 & 1.7 & 1.8 & 1.1 & 2.0 & 1.4 & 1.6 & 1.3 & 1.0 \\
\hline 24 & 1.4 & 1.1 & 1.1 & 1.7 & 1.5 & 1.7 & 1.1 & 1.3 & 1.7 & 1.6 & 1.8 \\
\hline 25 & 1.7 & 1.2 & 1.1 & 1.6 & 1.2 & 2.0 & 1.9 & 1.0 & 1.1 & 1.2 & 1.2 \\
\hline 27 & 1.1 & 1.6 & 2.0 & 1.5 & 1.7 & 1.1 & 1.8 & 1.1 & 1.8 & 1.5 & 1.5 \\
\hline 28 & 1.1 & 1.1 & 1.6 & 1.4 & 1.7 & 1.1 & 1.5 & 1.6 & 1.8 & 1.6 & 1.3 \\
\hline 29 & 1.1 & 1.1 & 1.5 & 2.0 & 1.6 & 1.4 & 2.0 & 1.1 & 1.3 & 2.0 & 1.4 \\
\hline & & & & & & & & & & & \\
\hline
\end{tabular}

Table 10. Processed data of oxygen sensor for the DEA approach

\begin{tabular}{|c|c|c|c|c|c|c|c|c|c|c|c|}
\hline \multirow{2}{*}{ Supplier } & \multicolumn{9}{|c|}{ Input } & \multicolumn{6}{|c|}{ Output } \\
\cline { 2 - 13 } & S1 & S2 & Q1 & C1 & T1 & Q2 & T3 & T2 & S3 & C2 & Q3 \\
\hline 2 & 1.5 & 1.3 & 1.3 & 1.8 & 1.3 & 1.0 & 1.9 & 1.7 & 1.8 & 1.3 & 1.8 \\
\hline 4 & 1.1 & 1.9 & 1.2 & 1.0 & 1.2 & 1.0 & 1.8 & 2.0 & 2.0 & 2.0 & 1.9 \\
\hline 6 & 1.5 & 1.1 & 1.2 & 1.8 & 1.4 & 1.1 & 1.3 & 1.2 & 1.0 & 1.1 & 1.8 \\
\hline 7 & 1.0 & 1.2 & 1.1 & 1.1 & 1.1 & 1.1 & 2.0 & 1.2 & 1.5 & 1.7 & 2.0 \\
\hline 8 & 2.0 & 1.0 & 2.0 & 1.6 & 1.7 & 2.0 & 1.0 & 1.3 & 1.5 & 1.7 & 1.9 \\
\hline 9 & 1.4 & 1.3 & 1.2 & 1.8 & 1.4 & 1.5 & 1.7 & 1.8 & 2.0 & 1.8 & 1.7 \\
\hline 11 & 1.2 & 1.1 & 1.3 & 1.6 & 1.1 & 1.0 & 2.0 & 2.0 & 1.9 & 1.0 & 1.9 \\
\hline 12 & 1.4 & 1.8 & 1.4 & 1.8 & 1.3 & 1.4 & 1.7 & 1.3 & 1.3 & 1.3 & 1.0 \\
\hline 14 & 1.5 & 1.0 & 1.5 & 1.3 & 2.0 & 1.5 & 2.0 & 1.7 & 1.1 & 1.2 & 1.9 \\
\hline 15 & 1.4 & 1.0 & 1.3 & 1.6 & 1.3 & 1.2 & 1.0 & 1.8 & 1.5 & 1.7 & 1.9 \\
\hline 17 & 1.8 & 2.0 & 1.4 & 1.8 & 1.3 & 1.8 & 1.1 & 1.5 & 1.1 & 1.2 & 1.8 \\
\hline 18 & 1.9 & 1.1 & 1.0 & 1.7 & 1.0 & 1.0 & 2.0 & 1.6 & 1.2 & 1.4 & 2.0 \\
\hline 21 & 1.6 & 1.1 & 1.2 & 1.3 & 1.6 & 1.1 & 2.0 & 1.1 & 1.4 & 1.8 & 1.8 \\
\hline 23 & 1.9 & 1.9 & 1.0 & 1.8 & 1.0 & 1.4 & 1.6 & 1.3 & 1.7 & 1.4 & 1.9 \\
\hline 25 & 1.8 & 1.6 & 1.4 & 1.6 & 2.0 & 2.0 & 1.9 & 1.3 & 1.0 & 1.0 & 1.9 \\
\hline 26 & 1.2 & 1.6 & 1.2 & 1.7 & 1.1 & 1.1 & 1.8 & 1.4 & 2.0 & 1.8 & 1.8 \\
\hline 28 & 1.0 & 1.3 & 1.0 & 1.4 & 1.1 & 1.3 & 1.9 & 1.3 & 1.8 & 1.8 & 1.8 \\
\hline 29 & 1.2 & 1.0 & 1.8 & 2.0 & 2.0 & 1.4 & 1.4 & 1.0 & 1.1 & 1.2 & 1.8 \\
\hline 30 & 1.0 & 1.9 & 1.8 & 1.2 & 1.4 & 1.4 & 1.6 & 1.2 & 1.5 & 1.8 & 2.0 \\
\hline
\end{tabular}


Table 11. Processed data of crankshaft for the DEA approach

\begin{tabular}{|c|c|c|c|c|c|c|c|c|c|c|c|}
\hline \multirow{2}{*}{ Supplier } & \multicolumn{7}{|c|}{ Input } & \multicolumn{5}{|c|}{ Output } \\
\cline { 2 - 13 } & $\mathrm{S}^{*}$ & $\mathrm{~S}^{*}$ & $\mathrm{Q}^{*}$ & $\mathrm{C}^{*}$ & $\mathrm{~T}^{*}$ & $\mathrm{Q}^{*}$ & $\mathrm{Q}^{*}$ & $\mathrm{~S}^{*}$ & $\mathrm{C}^{*}$ & $\mathrm{~S}^{*}$ & $\mathrm{C}^{*}$ \\
\hline 1 & 1.5 & 1.0 & 1.2 & 1.7 & 1.6 & 1.1 & 1.5 & 2.0 & 2.0 & 2.0 & 1.8 \\
\hline 3 & 2.0 & 1.8 & 1.1 & 1.7 & 1.7 & 1.6 & 1.8 & 2.0 & 1.6 & 2.0 & 1.5 \\
\hline 5 & 1.4 & 2.0 & 1.5 & 1.7 & 1.7 & 1.1 & 2.0 & 1.5 & 2.0 & 1.9 & 1.2 \\
\hline 7 & 1.0 & 1.0 & 1.2 & 1.0 & 1.6 & 1.0 & 1.6 & 1.5 & 1.7 & 1.7 & 1.9 \\
\hline 9 & 1.3 & 1.5 & 1.3 & 1.7 & 1.6 & 1.3 & 1.0 & 2.0 & 1.9 & 1.6 & 1.4 \\
\hline 10 & 1.3 & 1.1 & 1.8 & 1.4 & 1.3 & 1.0 & 2.0 & 1.1 & 1.5 & 1.6 & 2.0 \\
\hline 12 & 1.4 & 2.0 & 1.6 & 1.8 & 2.0 & 1.4 & 1.5 & 1.3 & 1.5 & 2.0 & 1.7 \\
\hline 14 & 1.5 & 1.1 & 1.3 & 1.1 & 1.5 & 1.4 & 1.4 & 1.3 & 1.1 & 1.9 & 1.5 \\
\hline 16 & 1.6 & 1.1 & 1.7 & 1.6 & 1.6 & 1.0 & 1.0 & 1.0 & 1.5 & 1.6 & 1.0 \\
\hline 18 & 1.8 & 1.2 & 1.1 & 1.7 & 1.5 & 1.1 & 2.0 & 1.3 & 1.4 & 1.0 & 1.2 \\
\hline 20 & 1.3 & 1.0 & 1.0 & 1.5 & 1.0 & 1.1 & 1.9 & 1.8 & 1.2 & 1.8 & 1.2 \\
\hline 22 & 1.6 & 1.3 & 1.6 & 1.7 & 2.0 & 1.1 & 1.9 & 1.5 & 1.5 & 1.4 & 1.1 \\
\hline 23 & 1.8 & 1.7 & 1.1 & 1.7 & 1.3 & 1.4 & 1.8 & 1.7 & 1.5 & 1.7 & 1.6 \\
\hline 25 & 1.7 & 1.3 & 1.2 & 1.6 & 1.3 & 2.0 & 1.8 & 1.1 & 1.0 & 1.2 & 1.2 \\
\hline 27 & 1.0 & 1.6 & 2.0 & 1.4 & 1.8 & 1.2 & 1.8 & 1.1 & 1.8 & 1.5 & 1.5 \\
\hline 29 & 1.0 & 1.0 & 1.5 & 2.0 & 1.8 & 1.5 & 2.0 & 1.3 & 1.1 & 1.9 & 1.5 \\
\hline
\end{tabular}

We use the models (4), (5) and the formula (6) mentioned in Section 3 to obtain the crossefficiency matrix (CEM), and then calculate the column means and the row means of the CEM with the formulas (7) and (8) for each component. Here, the column means of the CEM represent suppliers' comparative performance; the row means of the CEM represent suppliers' diversity performance. In the view of the company's decision makers, candidate suppliers should certainly own high comparative performance and low diversity performance. The graphical representation for comparative performance and diversity performance of potential suppliers is illustrated in Figure 3 and the numerical values are given in Tables 26 to 29 in the Appendix. In order to screen potential suppliers, buyers wish to obtain a comprehensive overall performance for each supplier which simultaneously contains the two dimensions of performance. The weights assigned for comparative performance and diversity performance of sensor components and engine components are $(0.4,0.6)$ and $(0.7,0.3)$ accordingly.

Then, we build the weight matrix for the four components and use Eq. (12) and (13) in Section 3 to get the ideal solutions for comparative performance and diversity performance, the results are shown in Table 12.

Table 12. Ideal solutions for comparative performance and diversity performance

\begin{tabular}{|c|c|c|c|c|}
\hline \multirow{2}{*}{ Ideal solution } & \multicolumn{4}{|c|}{ Component } \\
\cline { 2 - 5 } & $\mathrm{A}$ & $\mathrm{B}$ & $\mathrm{C}$ & $\mathrm{D}$ \\
\hline$v_{j}^{+}$ & $(0.13,0.09)$ & $(0.20,0.04)$ & $(0.12,0.09)$ & $(0.24,0.05)$ \\
\hline$v_{j}^{-}$ & $(0.07,0.17)$ & $(0.11,0.08)$ & $(0.06,0.17)$ & $(0.13,0.09)$ \\
\hline
\end{tabular}

Note: A - intake air pressure sensor; B - oil injection nozzle; C - oxygen sensor; D - crankshaft. 
(A)

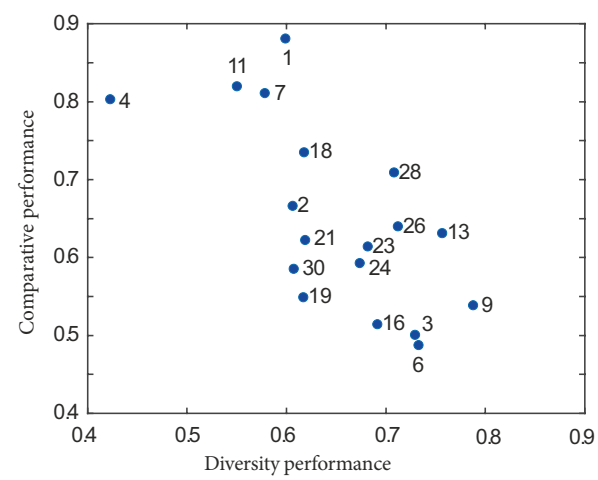

(C)

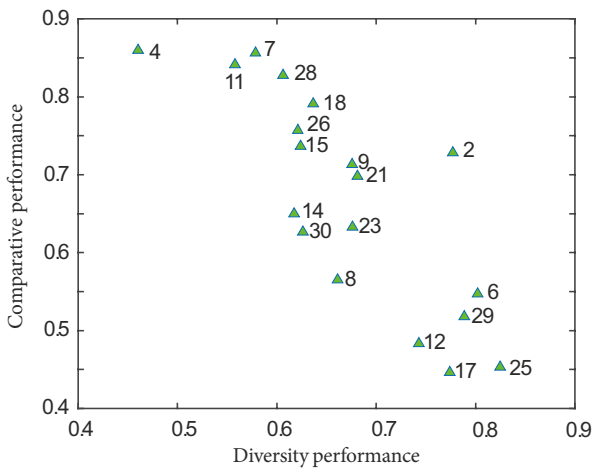

(B)

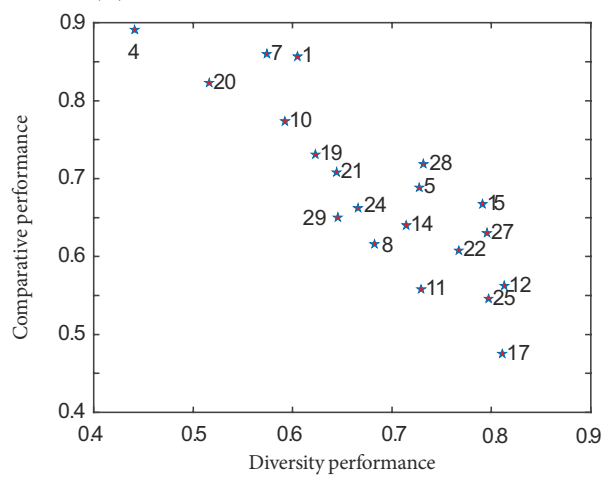

(D)

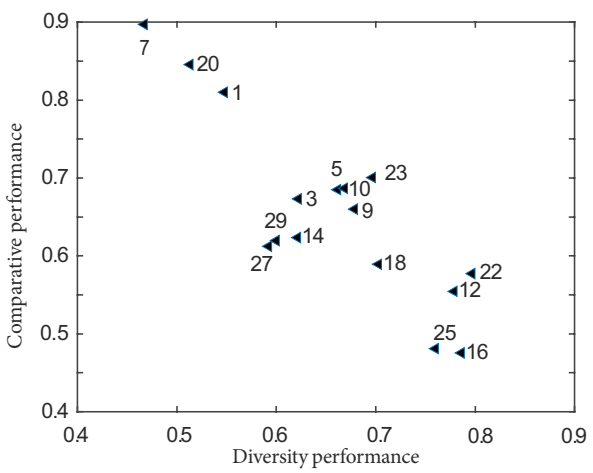

Figure 3. Comparative and diversity performance for the four components

Note: A - intake air pressure sensor; B - oil injection nozzle; C - oxygen sensor; D - crankshaft.

On top of that, we calculate the overall performance of potential suppliers for components A to D which are shown in Table 13. According to the results, potential suppliers will be classified into four categories. Suppliers in the top quartile are excellent performers and they are considered as long-term partners; suppliers in the second quartile are qualified for developing similar new products but still need improvement; suppliers in the third quartile are suggested for delaying development of new product in the next quarter and they are required to make rectifications; suppliers in the bottom quartile are the worst performers which should be weeded out from the company's supplier base.

In this case, the suppliers are classified into grades M1 to M4. Strategies include "encouragement", "improvement", "rectification" and "elimination" which will be carried out for the four grades. The management requirements and performance implications for the four grades are shown in Table 14. 
Table 13. Overall performance for components A to D of all potential suppliers

\begin{tabular}{|c|c|c|c|c|}
\hline \multirow{2}{*}{ Suppliers } & \multicolumn{4}{|c|}{ Component } \\
\hline & A & B & $\mathrm{C}$ & $\mathrm{D}$ \\
\hline 1 & $0.646^{(\mathrm{I})}$ & $0.834^{(\mathrm{I})}$ & - & $0.789^{(\mathrm{I})}$ \\
\hline 2 & $0.483^{(\mathrm{II})}$ & - & $0.369^{(\mathrm{III})}$ & - \\
\hline 3 & $0.130^{(\mathrm{IV})}$ & - & - & $0.475^{\text {(II) }}$ \\
\hline 4 & $0.891^{(\mathrm{I})}$ & $1^{(\mathrm{I})}$ & $1^{(\mathrm{I})}$ & - \\
\hline 5 & - & $0.477^{(\mathrm{II})}$ & - & $0.488^{(\mathrm{II})}$ \\
\hline 6 & $0.119^{(\mathrm{IV})}$ & - & $0.150^{\text {(IV) }}$ & - \\
\hline 7 & $0.649^{(\mathrm{I})}$ & $0.860^{(\mathrm{I})}$ & $0.756^{(\mathrm{I})}$ & $1^{(\mathrm{I})}$ \\
\hline 8 & - & $0.340^{(\mathrm{III})}$ & $0.394^{(\mathrm{III})}$ & - \\
\hline 9 & $0.073^{(\mathrm{IV})}$ & - & $0.493^{(\mathrm{III})}$ & $0.430^{\text {(II) }}$ \\
\hline 10 & - & $0.700^{(\mathrm{I})}$ & - & $0.490^{\text {(II) }}$ \\
\hline 11 & $0.708^{(\mathrm{I})}$ & $0.203^{(\mathrm{IV})}$ & $0.791^{(\mathrm{I})}$ & - \\
\hline 12 & - & $0.193^{(\mathrm{IV})}$ & $0.185^{(\mathrm{IV})}$ & $0.178^{(\mathrm{IV})}$ \\
\hline 13 & $0.212^{(\mathrm{IV})}$ & - & - & - \\
\hline 14 & - & $0.381^{(\mathrm{III})}$ & $0.541^{(\mathrm{II})}$ & $0.371^{(\mathrm{III})}$ \\
\hline 15 & - & $0.416^{(\mathrm{III})}$ & $0.603^{(\mathrm{II})}$ & - \\
\hline 16 & $0.213^{(\mathrm{III})}$ & - & - & $0.010^{\text {(IV) }}$ \\
\hline 17 & - & $0.002^{(I V)}$ & $0.109^{(\mathrm{IV})}$ & - \\
\hline 18 & $0.521^{(\mathrm{II})}$ & - & $0.619^{(\mathrm{II})}$ & $0.271^{\text {(III) }}$ \\
\hline 19 & $0.375^{(\mathrm{II})}$ & $0.601^{(\mathrm{II})}$ & - & - \\
\hline 20 & - & $0.831^{(\mathrm{I})}$ & - & $0.876^{(\mathrm{I})}$ \\
\hline 21 & $0.424^{(\mathrm{II})}$ & $0.546^{(\mathrm{II})}$ & $0.472^{\text {(III) }}$ & - \\
\hline 22 & - & $0.297^{(\mathrm{IV})}$ & - & $0.225^{\text {(IV) }}$ \\
\hline 23 & $0.301^{(\mathrm{III})}$ & - & $0.424^{(\mathrm{III})}$ & $0.510^{(\mathrm{I})}$ \\
\hline 24 & $0.298^{(\mathrm{III})}$ & $0.443^{(\mathrm{II})}$ & - & - \\
\hline 25 & - & $0.158^{(\mathrm{IV})}$ & $0.010^{(\mathrm{IV})}$ & $0.037^{\text {(IV) }}$ \\
\hline 26 & $0.276^{(\mathrm{III})}$ & - & $0.624^{(\mathrm{II})}$ & - \\
\hline 27 & - & $0.339^{(\mathrm{III})}$ & - & $0.359^{(\mathrm{III})}$ \\
\hline 28 & $0.352^{(\mathrm{III})}$ & $0.537^{(\mathrm{II})}$ & $0.693^{(\mathrm{I})}$ & - \\
\hline 29 & - & $0.425^{(\mathrm{III})}$ & $0.130^{(\mathrm{IV})}$ & $0.371^{(\mathrm{III})}$ \\
\hline 30 & $0.416^{(\mathrm{II})}$ & - & $0.506^{(\mathrm{II})}$ & - \\
\hline
\end{tabular}

Note: I - Grade M1; II - Grade M2; III - Grade M3; IV - Grade M4. 
Table 14. Management requirements and performance implications for the four grades

\begin{tabular}{|l|l|l|}
\hline Grade & $\begin{array}{c}\text { Level of } \\
\text { requirements }\end{array}$ & \multicolumn{1}{c|}{ Performance implications } \\
\hline M1 & Encouragement & $\begin{array}{l}\text { 1. Obtain opportunity for supply increase, and have preferential access to } \\
\text { new component development } \\
\text { 2. Obtain opportunity for order allocations } \\
\text { 3. Obtain opportunity for being selected as an excellent supplier in } \\
\text { current year }\end{array}$ \\
\hline M2 & Improvement & $\begin{array}{l}\text { 1. Be qualified for developing similar new products } \\
\text { 2. Reduce awards if failing to meet the standards of grade M2 for two } \\
\text { consecutive months } \\
\text { 3. Submit a rectification report if the quality evaluation score is less than } \\
\text { forty }\end{array}$ \\
\hline M3 & Rectification & $\begin{array}{l}\text { 1. Fall to M4 if the evaluation remains at M3 for three months } \\
\text { 2. Explain the problems to the sourcing company } \\
\text { 3.Be suggested for delaying development of new product in the next } \\
\text { quarter }\end{array}$ \\
\hline M4 & Elimination & $\begin{array}{l}\text { 1. Pay evaluation management fees and explain the problems to the } \\
\text { sourcing company } \\
\text { 2. Be suggested for delaying development of new product in the next six } \\
\text { months } \\
\text { 3. Be removed if evaluation remains at M4 for three months }\end{array}$ \\
\hline
\end{tabular}

Table 15. Rank of potential suppliers for the components A-D

\begin{tabular}{|l|l|}
\hline $\mathrm{A}$ & $S_{4}>S_{11}>S_{7}>S_{1}>S_{18}>S_{2}>S_{21}>S_{30}>S_{19}>S_{28}>S_{23}>S_{24}>S_{26}>S_{16}>S_{13}>S_{3}>S_{6}>S_{9}$ \\
\hline $\mathrm{B}$ & $S_{4}>S_{7}>S_{1}>S_{20}>S_{10}>S_{19}>S_{21}>S_{28}>S_{5}>S_{24}>S_{29}>S_{15}>S_{14}>S_{8}>S_{27}>S_{22}>S_{11}>S_{12}>S_{25}>S_{17}$ \\
\hline $\mathrm{C}$ & $S_{4}>S_{11}>S_{7}>S_{28}>S_{26}>S_{18}>S_{15}>S_{14}>S_{30}>S_{9}>S_{21}>S_{23}>S_{8}>S_{2}>S_{12}>S_{6}>S_{29}>S_{17}>S_{25}$ \\
\hline $\mathrm{D}$ & $S_{7}>S_{20}>S_{1}>S_{23}>S_{10}>S_{5}>S_{3}>S_{9}>S_{29}>S_{14}>S_{27}>S_{18}>S_{22}>S_{12}>S_{25}>S_{16}$ \\
\hline
\end{tabular}

Note: A - intake air pressure sensor; B - oil injection nozzle; C - oxygen sensor; D - crankshaft.

Thus, we rank suppliers for the four components in Table 15. Decision makers decide to choose top four suppliers as candidates to allocate orders for each component. Then, we select suppliers 4,11,1,7 for intake air pressure sensor; suppliers 4,7,20,1 for oil injection nozzle; suppliers 4,11,7,28 for oxygen sensor; and suppliers 7,20,1,23 for crankshaft.

\subsection{Order allocations for candidate suppliers}

In this case, decision makers wish to choose no more than two suppliers among the four candidates to allocate orders. The candidate suppliers give important parameters that are triangular fuzzy capacity for components, defect rate for the components, fixed and variable cost, triangular fuzzy lead times as well as all-unit quantity discounts. The values for these parameters are shown in Tables 30 to 34 in the Appendix. 
Then, we build the FMIP model with multiple objectives, and the steps of the algorithm to solve the model for each component are as follows:

Step 1. Defuzzy the triangular fuzzy values of demand, capacity and lead times. The values of defuzzification of demand for the components A to D are $(2083.3,2433.3,1983.3$, 2567.7). The defuzzification results of lead times and capacity are shown in Table 16 and Table 17.

Table 16. Defuzzification of fuzzy lead times

\begin{tabular}{|c|c|c|c|c|}
\hline \multirow{2}{*}{ Supplier } & \multicolumn{4}{|c|}{ Delivery time } \\
\cline { 2 - 5 } & A & C & B & D \\
\hline 1 & 7.7 & - & 7.7 & 9.3 \\
\hline 4 & 8 & 6.3 & 7 & - \\
\hline 7 & 6 & 8 & 6.3 & - \\
\hline 11 & 6.7 & 5.7 & - & 6.7 \\
\hline 20 & - & - & 7.7 & 6.3 \\
\hline 23 & - & - & - & - \\
\hline 28 & - & 7.3 & - & \\
\hline
\end{tabular}

Table 17. Defuzzification of fuzzy capacity

\begin{tabular}{|c|c|c|c|c|}
\hline \multirow{2}{*}{ Supplier } & \multicolumn{4}{|c|}{ Capacity } \\
\cline { 2 - 5 } & A & C & B & D \\
\hline 1 & 1483.3 & - & 1633.3 & 1516.7 \\
\hline 4 & 1750 & 1516.7 & 1583.3 & - \\
\hline 7 & 1500 & 1633.3 & 1716.7 & 1383.3 \\
\hline 11 & 1666.7 & 1716.7 & 1783.3 & - \\
\hline 20 & - & - & - & 1716.7 \\
\hline 23 & - & - & - & 1933.3 \\
\hline 28 & - & 1416.7 & - & - \\
\hline
\end{tabular}

Step 2. Solve a single objective function model by using the max-min approach (Zimmermann, 1978) for each objective function of the model for each component. The results are listed in Table 18.

Table 18. Max-min objective values for the components A-D

\begin{tabular}{|c|c|c|c|c|c|c|}
\hline \multirow{2}{*}{ Component } & \multicolumn{2}{|c|}{$f_{1}$} & \multicolumn{2}{c|}{$f_{2}$} & \multicolumn{2}{c|}{$f_{3}$} \\
\cline { 2 - 7 } & Max & Min & Max & Min & Max & Min \\
\hline A & 334475.4 & 286727.8 & 55.0 & 22.9 & 50705 & 0 \\
\hline B & 85088.1 & 78470.5 & 13.1 & 10.5 & 6350.4 & 0 \\
\hline C & 444476.6 & 420613.7 & 58.6 & 43.6 & 48256.7 & 7954.3 \\
\hline D & 110494.2 & 100753.8 & 15.5 & 6.2 & 45907.6 & 0 \\
\hline
\end{tabular}

Note: $f_{1}$ - cost; $f_{2}$ - unqualified items; $f_{3}$ - delivery penalty. 
Step 3. Build the membership functions for the fuzzy objectives and fuzzy demand constraints on the basis of the max-min objective values obtained in Step 2, and the graphical membership functions for each component are shown in Figures 4 and 5.

Step 4. Collect weights for the objectives and the constraints from the decision makers, and the weight values for each component are $(0.15,0.3,0.4,0.15)$.

Step 5. Reformulate the modified FMIP model as a crisp single objective model and find the optimal solution for each component.

(A.1)

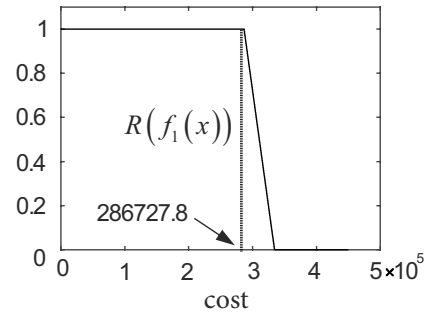

(B.1)

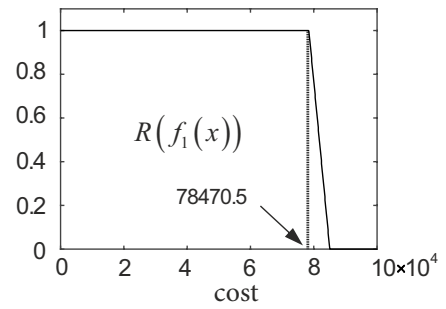

(C.1)

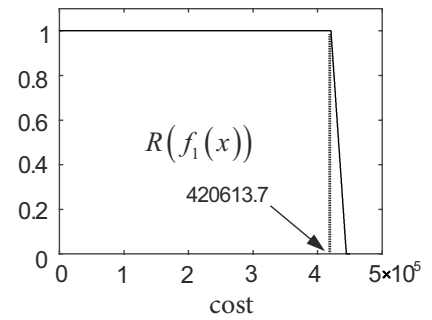

(D.1)

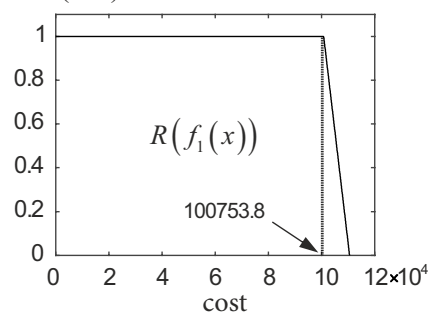

(A.2)

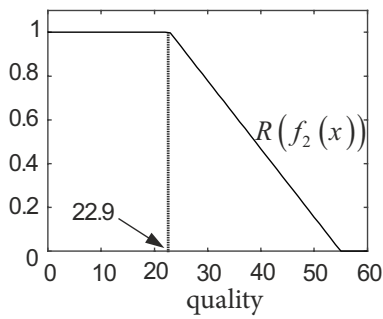

(B.2)

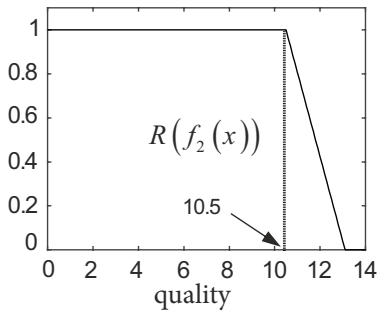

(C.2)

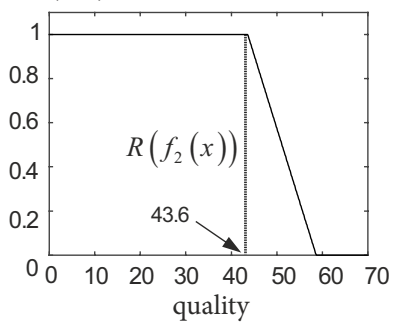

(D.2)

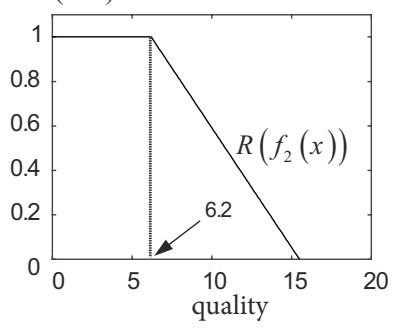

(A.3)

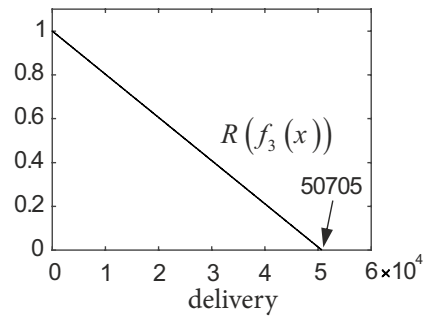

(B.3)

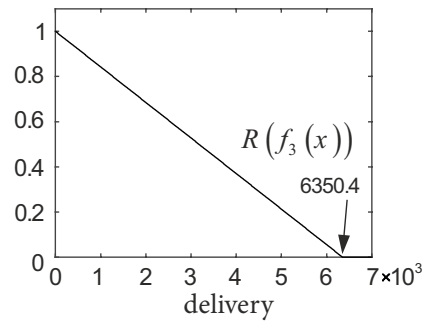

(C.3)

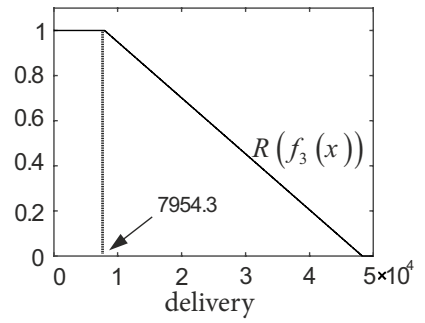

(D.3)

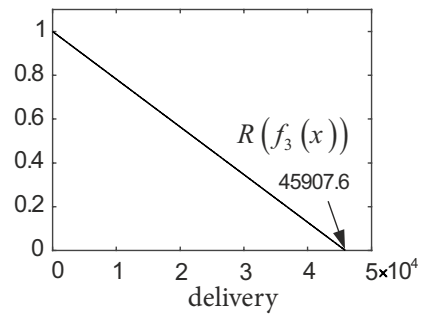

Figure 4. Membership functions of the three objectives: (A.1-A.3): $f_{1}$ to $f_{3}$ for component A; (B.1-B.3): $f_{1}$ to $f_{3}$ for component B; (C.1-C.3): $f_{1}$ to $f_{3}$ for component C;

(D.1-D.3): $f_{1}$ to $f_{3}$ for component D 
(A)

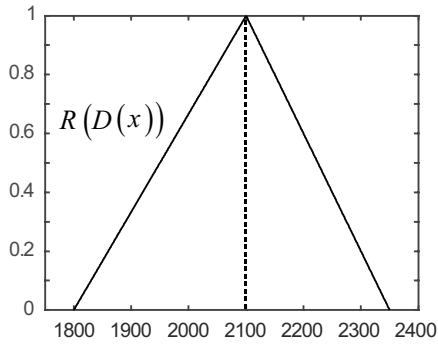

(C)

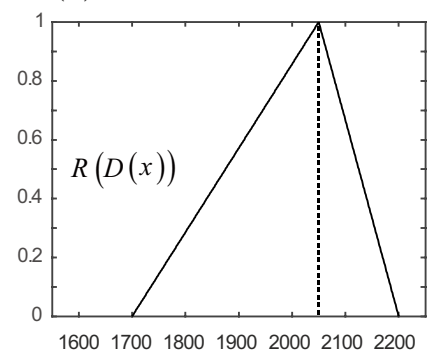

(B)

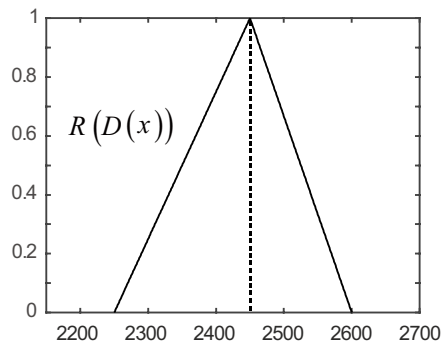

(D)

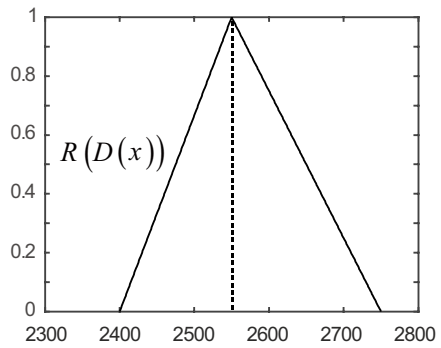

Figure 5. Membership functions for demand: (A) Demand for component A;

(B) Demand for component B; (C) Demand for component C; (D) Demand for component D

The single objective model has been solved on a Pentium $(2.9 \mathrm{GHz})$ personal computer. The results are obtained by the branch and bound approach (Land \& Doig, 1960) in LINGO 15.0 and the order allocations for the four components are shown in Table 19 and Table 20.

Table 19. Results of the extended FMIP model for order allocations

\begin{tabular}{|c|c|c|c|c|c|c|c|c|c|}
\hline \multirow{2}{*}{ Component } & \multicolumn{7}{|c|}{ Orders for suppliers } & \multirow{2}{*}{$f$ values } \\
\cline { 2 - 11 } & 1 & 2 & 4 & 7 & 10 & 11 & 20 & 28 & \\
\hline A & 0 & 0 & 447 & - & - & 1666 & - & - & $f_{1}=324115.4, f_{2}=29.5, f_{3}=12963.0$ \\
\hline B & 0 & - & 1583 & 862 & - & - & 0 & - & $f_{1}=82198.5, f_{2}=11.4, f_{3}=0$ \\
\hline C & - & - & 1515 & 0 & - & 0 & - & 525 & $f_{1}=425787.9, f_{2}=55.9, f_{3}=7969.5$ \\
\hline D & 0 & - & - & 863 & 0 & - & 1716 & - & $f_{1}=100753.8, f_{2}=11.2, f_{3}=4893.2$ \\
\hline
\end{tabular}

Note: $f_{1}$ - cost; $f_{2}$ - unqualified items; $f_{3}$ - delivery penalty.

Table 20. Achievement levels for objectives and demand constraint

\begin{tabular}{|c|c|c|c|c|c|}
\hline Component & Cost & Quality & Delivery & Demand & Overall \\
\hline A & $21.7 \%$ & $79.4 \%$ & $74.5 \%$ & $94.5 \%$ & $71.0 \%$ \\
\hline B & $30.4 \%$ & $66.9 \%$ & $100 \%$ & $91.8 \%$ & $78.4 \%$ \\
\hline C & $73.4 \%$ & $17.8 \%$ & $100 \%$ & $81.2 \%$ & $70.0 \%$ \\
\hline D & $100 \%$ & $46.7 \%$ & $89.3 \%$ & $91.1 \%$ & $78.4 \%$ \\
\hline
\end{tabular}


Accordingly, decision makers will select suppliers 4, 11 for component A; suppliers 4, 7 for component B; suppliers 28, 4 for component C; suppliers 7, 20 for component D to allocate the orders. According to the total purchase quantities, decision makers will allocate the most orders to the supplier 4 , the fewest orders to the supplier 28 . The actual purchase quantities of components A to D are $(2108,2445,2040,2579)$. We conclude that the proportion of purchase quantity exceeding demand for components A to D are all less than $3 \%$, so the purchase quantity should not only meet the demand but also have a certain quantity surplus for the uncertain market. It is clear that the achievement levels for the three objectives and the demand constraints cannot simultaneously exceed $81 \%$ which proves that the achievement of certain objectives is at the expense of deterioration in others. Take component $\mathrm{B}$ for example, the excellent achievement of delivery is at the expense of deterioration in cost and quality. Meanwhile, the overall achievement levels for components A to D are all higher than $70 \%$ which indicates that the results are certainly satisfied for the decision makers.

\section{Discussions}

To validify the DEA-TOPSIS-FMIP approach, we compare the rankings and categories of potential suppliers for components A to D by using the DEA-TOPSIS approach with those by using the DEA approach only. We also conduct sensitivity analysis to examine how objective values may vary with the objective weights in the FMIP model. These are detailed in the following.

\subsection{Comparison of the DEA-TOPSIS approach and the DEA approach alone}

The purpose of this analysis is to prove that the DEA-TOPSIS approach improves the DEA approach alone for supplier ranking. We illustrate potential suppliers' rankings and categories by these two approaches for components $A$ to $D$ in Figure 6, where we find that overall rankings of suppliers by these two approaches are different for each component. Take suppliers rankings in category $\mathrm{M} 1$ as an example, the rankings are the same for components $\mathrm{B}$ and $\mathrm{D}$ but different for components A and C. As shown in Table 26, the comparative performance and diversity performance for suppliers $4,11,7,1$ of component $A$ are $(0.80,0.82,0.81$, $0.88)$ and $(0.42,0.55,0.58,0.60)$; and the rankings of suppliers for component $\mathrm{A}$ by the DEA approach and the DEA-TOPSIS approach are $\mathrm{S}_{1}>\mathrm{S}_{11}>\mathrm{S}_{7}>\mathrm{S}_{4}$ and $\mathrm{S}_{4}>\mathrm{S}_{11}>\mathrm{S}_{7}>\mathrm{S}_{1}$ respectively. The ranking orders for supplier 1 and supplier 4 are opposite by the two approaches.

We argue that the results by the DEA-TOPSIS approach are better informed and therefore more valuable than those by the DEA approach alone, because the supplier rankings by the DEA approach is solely based on suppliers' comparative performance, while the DEATOPSIS approach is based on the overall performances that integrate the comparative performance and the diversity performance of suppliers. Figure 6 shows that the variation range of suppliers' overall performance by the DEA-TOPSIS approach is much wider than by the DEA approach alone. This reflects that the DEA-TOPSIS approach utilizes more information that has effects on the results, and therefore leads to more accurate rankings and categories of suppliers than the DEA approach. 

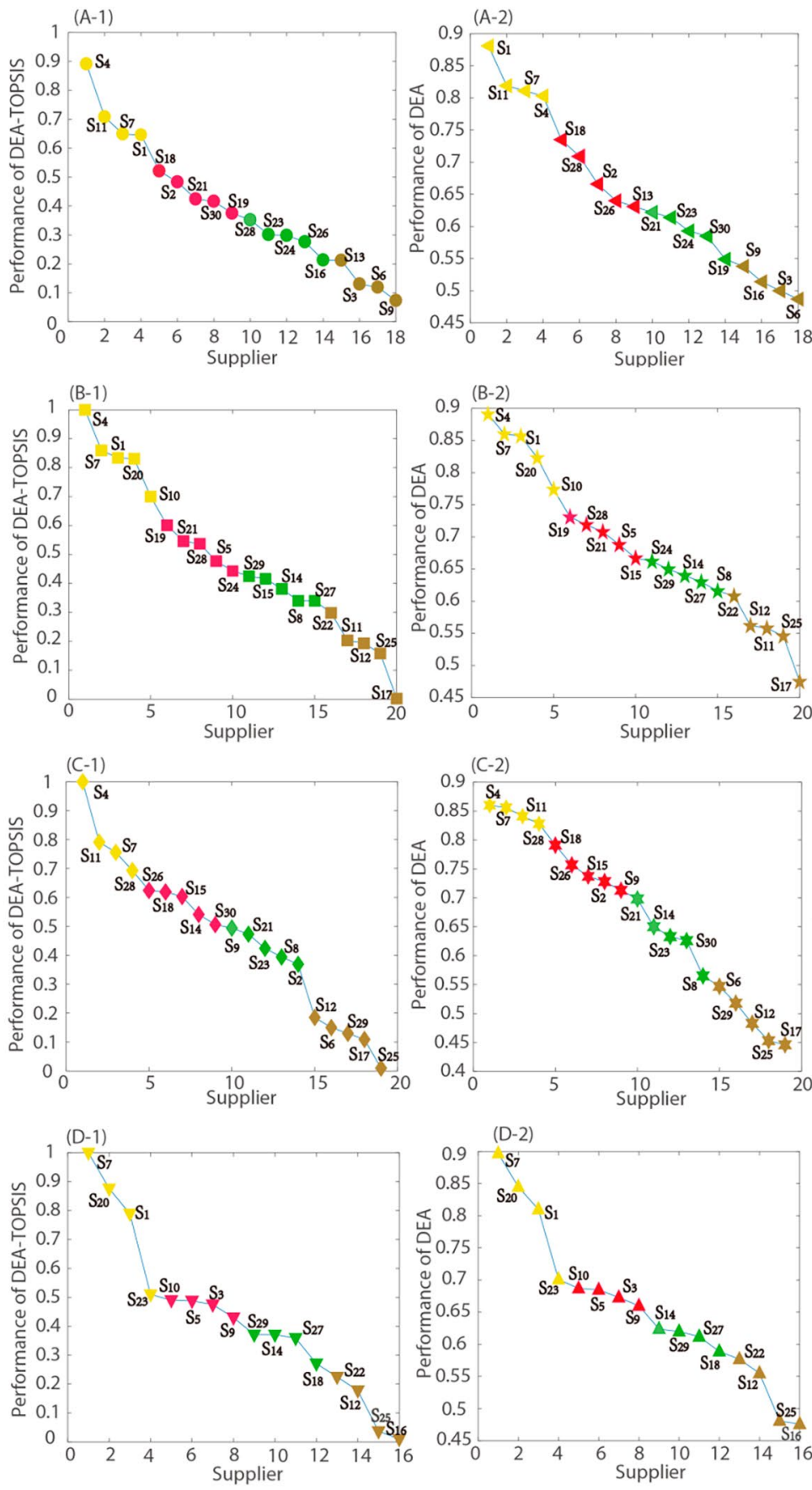

(D-2)

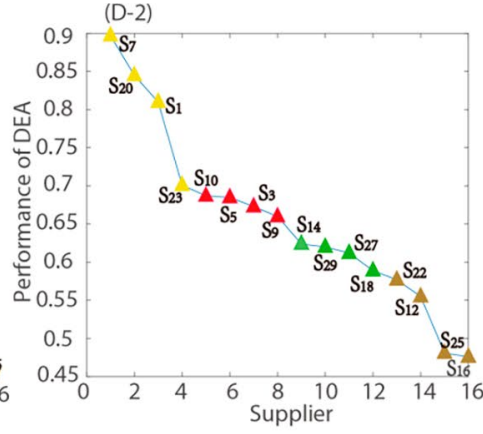

Grade M1

Grade M3 $\diamond$ Grade M4

Figure 6. Supplier rankings and categories for components A-D under DEA-TOPSIS and DEA approaches

Note: A - intake air pressure sensor; B - oil injection nozzle; C - oxygen sensor; D - crankshaft. 


\subsection{Sensitivity of weights in the FMIP model}

To assure the robustness of the model, we examine the effects of changing weights on the objective values, the analyses are made for each component separately. In order to analyze the influence of the different priorities of cost, quality, delivery and demand on procurement, we utilize four cases reflecting different priorities, i.e. weight values as in Table 21 for sensitivity analysis. The solutions for components A to D in these four cases are shown in Figure 7, and the achievement levels for demand fulfillment are shown in Figure 8.

Table 21. Weights of objectives and demand constraints for the four cases

\begin{tabular}{|c|c|c|c|c|}
\hline Case & Cost & Quality & Delivery & Demand \\
\hline 1 & 0.18 & 0.3 & 0.37 & 0.15 \\
\hline 2 & 0.15 & 0.23 & 0.25 & 0.37 \\
\hline 3 & 0.24 & 0.41 & 0.16 & 0.19 \\
\hline 4 & 0.38 & 0.16 & 0.2 & 0.26 \\
\hline
\end{tabular}

(A)

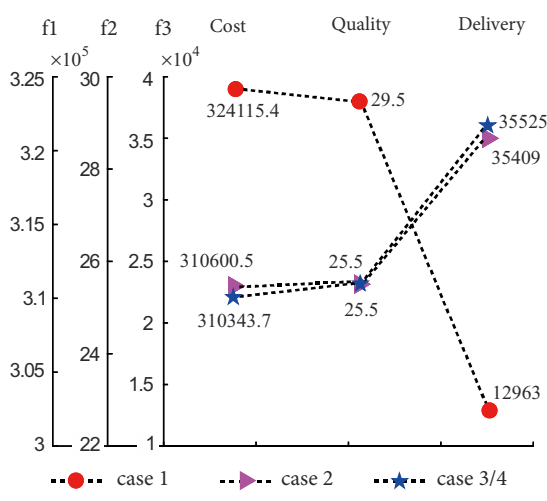

(C)

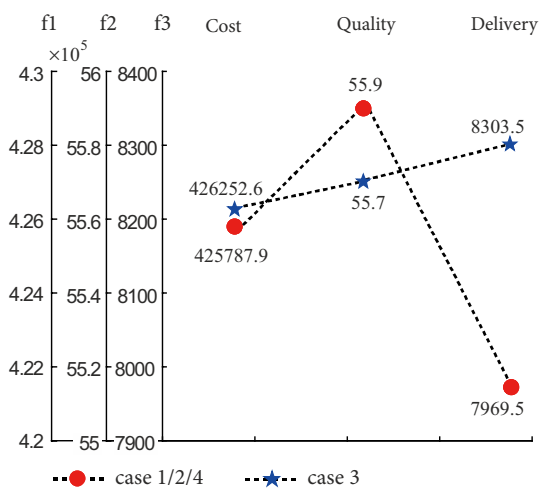

(B)

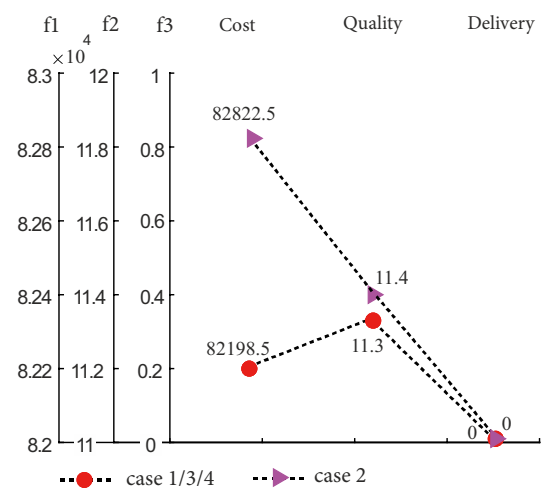

(D)

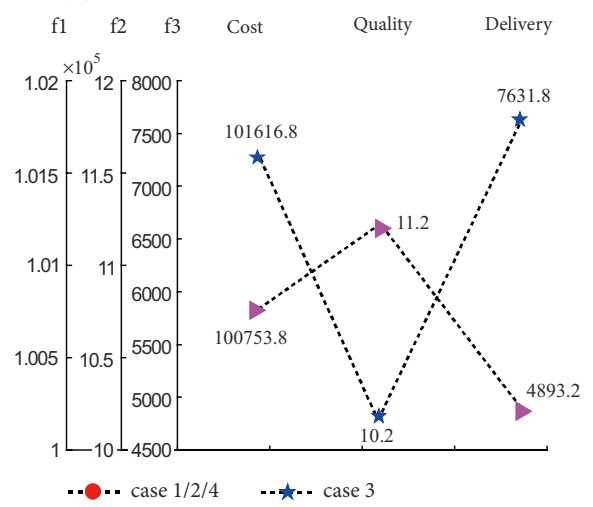

Figure 7. Solutions of the four cases - for the three objectives of cost, quality and delivery Note: A - intake air pressure sensor; B - oil injection nozzle; C - oxygen sensor; D - crankshaft; f1 - cost; f2 - unqualified items; f3 - delivery penalty. 


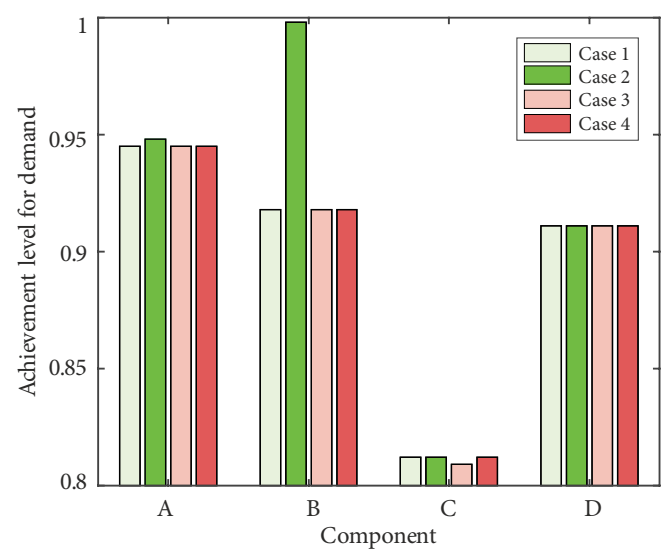

Figure 8. Demand achievement levels of components A-D for four cases of priorities

Since the highest priority of delivery is assigned in Case 1, we get the lowest delivery delay penalties for components A to D that are 12963, 0, 7969.5 and 4893.2 (RMB) as seen in Figure 7. Due to the highest priority of demand obtained in Case 2, we obtain the highest demand achievement levels in Case 2 for components A to D that are $94.8 \%, 99.8 \%, 81.2 \%$, and $91.1 \%$ as seen in Figure 8. Likewise, the best qualities are achieved in Case 3 that are $25.5,11.3,55.7$ and 10.2, given that the highest priority on quality is assigned in this case; and the lowest costs are obtained in Case 4 which are 324115.4, 82198.5, 425787.9, and 100753.8 (RMB) for the procurement of each component accordingly. Therefore, the changes in objective weights priorities do not necessarily lead to the changes in the objective values or its achievement level.

It is worth noting that a variation in priorities of the objectives will not always result in a variation in the optimal solutions. For example, Case 3 and Case 4 share the same optimal solutions for the components A and B; meanwhile, Case 1, Case 2 and Case 4 share the same optimal solutions for the components $\mathrm{C}$ and $\mathrm{D}$.

\section{Conclusions}

This paper proposes an improved solution for automobile components procurement decision-making with fuzzy variables and all-unit quantity discount policy, posed by the case of Chongqing SOKON Industry Group Stock Corporation Ltd in China. It contains DEATOPSIS procedures for ranking suppliers, and a subsequent FMIP approach for optimizing order allocations with imprecise information and piecewise functions for discount policies in one toolbox. The former enables the "lost" information of diversity performance yielded from DEA cross-evaluation to be useful, besides the commonly adopted cross-efficiency scores, while the latter enhances the usability of the order allocation model in realistic conditions, by introducing a piecewise function of all-unit quantity discount policy as a part of cost objective, as discount policies are often applied in China due to market competitions; besides, the 
FMIP module also improves the time window mechanism, and makes it implementable in practice by aligning reasonable penalty in the time-window for punctuality objective.

Thus, the DEA-TOPSIS-FMIP approach architect results in more diversified but also more accurate ranking for potential suppliers than the DEA approach alone, and an enhanced usability for components procurement decision making in cases where discount policies and imprecise information in the form of fuzzy variables are related. This paper has overcome three limitations:

(1) Information loss of diversity performance is avoided, which improves the model.

(2) The problem of non-computability of a time-window mechanism to send back products when delivery is beyond time limit, is resolved by aligning realistic penalty linked with cost.

(3) The integrated architect of the model enables its usability starting from evaluation data for the suppliers till order allocation plans are made.

As an outlook for future research, the presented model can be investigated or extended in the following directions: (1) The weights of comparative performance and diversity performance and their influences on different types of products may be investigated, assuming that classical products may require more priorities on comparative performance, while innovative products may require more priorities on diversity performance; these may be worthy to be tested; (2) The prices of each component have been set fixed in this study, mechanisms on reaching price equilibrium between the components suppliers and automobile manufacturers may also add value to procurement decision-making; (3) What if inventory constraints, and financial dynamics are included as a part of the problem.

\section{Acknowledgements}

This work was supported by the National Natural Science Foundation of China under Grant Nos. 71771155 and 71571123.

\section{Author contributions}

Jiajia Chen conceived the study and was responsible for the design and development of the data analysis. Dongbin Huang were responsible for structure and revision of language. Jianchuan Zhang were responsible for data interpretation. Zeshui Xu and Xunjie Gou were responsible for the data collection and analysis. Jiajia Chen wrote the first draft of the article.

\section{Disclosure statement}

All authors have read and approve this version of the article, and due care has been taken to ensure the integrity of the work. No part of this paper has published or submitted elsewhere. No conflict of interest exits in the submission of this manuscript. 


\section{References}

Amid, A., Ghodsypour, S. H., \& O’Brien, C. (2006). Fuzzy multiobjective linear model for supplier selection in a supply chain. International Journal of Production Economics, 104(2), 394-407. https://doi.org/10.1016/j.ijpe.2005.04.012

Ayhan, M. B., \& Kilic, H. S. (2015). A two stage approach for supplier selection problem in multi-item/ multi-supplier environment with quantity discounts. Computers and Industrial Engineering, 85, 1-12. https://doi.org/10.1016/j.cie.2015.02.026

Amid, A., Ghodsypour, S. H., \& O’Brien, C. (2009). A weighted additive fuzzy multiobjective model for the supplier selection problem under price breaks in a supply Chain. International Journal of Production Economics, 121(2), 323-332. https://doi.org/10.1016/j.ijpe.2007.02.040

Aktin, T., \& Gergin, Z. (2016). Mathematical modelling of sustainable procurement strategies: Three case studies. Journal of Cleaner Production, 113, 767-780. https://doi.org/10.1016/j.jclepro.2015.11.057

Arabzad, S. M., Ghorbani, M., Razmi, J., \& Shirouyehzad, H. (2015). Employing fuzzy TOPSIS and SWOT for supplier selection and order allocation problem. The International Journal of Advanced Manufacturing Technology, 76(5-8), 803-818. https://doi.org/10.1007/s00170-014-6288-3

Bai, C. G., \& Sarkis, J. (2018). Integrating sustainability into supplier selection: a grey-based topsis analysis. Technological and Economic Development of Economy, 24(6), 2202-2224. https://doi.org/10.3846/tede.2018.5582

Bellman, R. E., \& Zadeh, L. A. (1970). Decision-making in fuzzy environment. Management Science, 17(4), 199-203. https://doi.org/10.1287/mnsc.17.4.B141

Bodaghi, G., Jolai, F., \& Rabbani, M. (2018). An integrated weighted fuzzy multi-objective model for supplier selection and order scheduling in a supply chain. International Journal of Production Research, 56(10), 3590-3614. https://doi.org/10.1080/00207543.2017.1400706

Bohner, C., \& Minner, S. (2017). Supplier selection under failure risk, quantity and business volume discounts. Computers \& Industrial Engineering, 104, 145-155. https://doi.org/10.1016/j.cie.2016.11.028

Charnes, A., Cooper W. W., \& Rhodes, E. (1978). Measuring efficiency of decision-making units. European Journal of Operational Research, 2(6), 429-444. https://doi.org/10.1016/0377-2217(78)90138-8

Cheraghalipour, A., \& Farsad, S. (2018). A bi-objective sustainable supplier selection and order allocation considering quantity discounts under disruption risks: a case study in plastic industry. Computers \& Industrial Engineering, 118, 237-250. https://doi.org/10.1016/j.cie.2018.02.041

Corbett, C. J. (2000). A Suppliers optimal quantity discount policy under asymmetric information. Management Science, 46(3), 444-450. https://doi.org/10.1287/mnsc.46.3.444.12065

Doyle, J., \& Green, R. (1994). Efficiency and cross-efficiency in DEA: Derivations, meanings and uses. Journal of the Operational Research Society, 45(5), 567-568. https://doi.org/10.1057/jors.1994.84

Freeman, J., \& Chen, T. (2015). Green supplier selection using an AHP-Entropy-TOPSIS framework. Supply Chain Management, 20(3), 327-340. https://doi.org/10.1108/SCM-04-2014-0142

Ghadimi, P., Dargi, A., \& Heavey, C. (2017). Making sustainable sourcing decisions: practical evidence from the automotive industry. International Journal of Logistics-Research and Applications, 20(4), 297-321. https://doi.org/10.1080/13675567.2016.1227310

Ghaniabadi, M., \& Mazinani, A. (2017). Dynamic lot sizing with multiple suppliers, backlogging and quantity discounts. Computers \& Industrial Engineering, 110, 67-74. https://doi.org/10.1016/j.cie.2017.05.031

Gupta, P., Govindan, K., Mehlawat, M. K., \& Kumar, S. (2016). A weighted possibilistic programming approach for sustainable vendor selection and order allocation in fuzzy environment. The International Journal of Advanced Manufacturing Technology, 86(5-8), 1785-1804.

https://doi.org/10.1007/s00170-015-8315-4 
Hamdan, S., \& Cheaitou, A. (2017a). Dynamic green supplier selection and order allocation with quantity discounts and varying supplier availability. Computers and Industrial Engineering, 110, 573-589. https://doi.org/10.1016/j.cie.2017.03.028

Hamdan, S., \& Cheaitou, A. (2017b). Green supplier selection and order allocation with incremental quantity discounts. In 2017 7th International Conference on Modeling, Simulation, and Applied Optimization, (ICMSAO). https://doi.org/10.1109/ICMSAO.2017.7934913

Homfeldt, F., Rese A., Brenner, H., Baier, D., \& Schaefer, T.F. (2017). Identification and generation of innovative ideas in the procurement of the automotive industry: the case of audi ag. International Journal of Innovation Management, 21(7), 1750053. https://doi.org/10.1142/S1363919617500530

Hwang, C. L., \& Yoon, K. P. (1981). Multiple attribute decision making: methods and applications (pp. 58-191). Springer-Verlag. https://doi.org/10.1007/978-3-642-48318-9

Ioannou, G., Kritikos, M., \& Prastacos, G. (2003). A problem generator-solver heuristic for vehicle routing with soft time windows. Omega, 31(1), 41-53. https://doi.org/10.1016/S0305-0483(02)00064-6

Land, A. H., \& Doig, A. G. (1960). An automatic method of solving discrete programming problem. Econometrica, 28(3), 497-520. https://doi.org/10.2307/1910129

Jadidi, O., Cavalieri, S., \& Zolfaghari, S. (2015). An improved multi-choice goal programming approach for supplier selection problems. Applied Mathematical Modelling, 39(14), 4213-4222. https://doi.org/10.1016/j.apm.2014.12.022

Jahangoshai Rezaee, M., Yousefi, S., \& Hayati, J. (2017). A multi-objective model for closed-loop supply chain optimization and efficient supplier selection in a competitive environment considering quantity discount policy. Journal of Industrial Engineering International, 13(2), 199-213. https://doi.org/10.1007/s40092-016-0178-2

Jauhar, S. K., \& Pant, M. (2017). Integrating DEA with de and mode for sustainable supplier selection. Journal of Computational Science, 21, 299-306. https://doi.org/10.1016/j.jocs.2017.02.011

Jin, Y., Ryan, J. K., \& Yund, W. (2014). Two stage procurement processes with competitive suppliers and uncertain supplier quality. IEEE Transactions on Engineering Management, 61(1), 147-158. https://doi.org/10.1109/TEM.2013.2266276

Keshavarz Ghorabaee, M. K., Amiri, M., Zavadskas, E. K., Turskis, Z., \& Antucheviciene, J. (2017). A new multi-criteria model based on interval type-2 fuzzy sets and edas method for supplier evaluation and order allocation with environmental considerations. Computers \& Industrial Engineering, 112, 156-174. https://doi.org/10.1016/j.cie.2017.08.017

Kumar, M., Vrat, P., \& Shankar, R. (2004). A fuzzy goal programming approach for vendor selection problem in a supply chain. Computers \& Industrial Engineering, 46(1), 69-85. https://doi.org/10.1016/j.cie.2003.09.010

Manerba, D., \& Perboli, G. (2019). New solution approaches for the capacitated supplier selection problem with total quantity discount and activation costs under demand uncertainty. Computers \& Industrial Engineering, 101, 29-42. https://doi.org/10.1016/j.cor.2018.08.010

Mazdeh, M. M., Emadikhiav, M., \& Parsa, I. (2015). A heuristic to solve the dynamic lot sizing problem with supplier selection and quantity discounts. Computers and Industrial Engineering, 85, 33-43. https://doi.org/10.1016/j.cie.2015.02.027

Memon, M. S., Lee, Y. H., \& Mari, S. I. (2015). Group multi-criteria supplier selection using combined grey systems theory and uncertainty theory. Expert Systems with Applications, 42(21), 7951-7959. https://doi.org/10.1016/j.eswa.2015.06.018

Mirzaee, H., Naderi, B., \& Pasandideh, S. H. R. (2018). A preemptive fuzzy goal programming model for generalized supplier selection and order allocation with incremental discount. Computers \& Industrial Engineering, 122, 292-302. https://doi.org/10.1016/j.cie.2018.05.042 
Moheb-Alizadeh, H., \& Handfield, R. (2019). Sustainable supplier selection and order allocation: A novel multi-objective programming model with a hybrid solution approach. Computers \& Industrial Engineering, 129, 192-209. https://doi.org/10.1016/j.cie.2019.01.011

Nazari-Shirkouhi, S., Shakouri, H., Javadi, B., \& Keramati, A. (2013). Supplier selection and order allocation problem using a two-phase fuzzy multi-objective linear programming. Applied Mathematical Modelling, 37(22), 9308-9323. https://doi.org/10.1016/j.apm.2013.04.045

Niroomand, S., Mahmoodirad, A., \& Mosallaeipour, S. (2019). A hybrid solution approach for fuzzy multiobjective dual supplier and material selection problem of carton box production systems. Expert Systems, 36(1), 1-17. https://doi.org/10.1111/exsy.12341

Pascual, R., Santelices, G., Lüer-Villagra, A., Vera, J., \& Cawley, A. M. (2017). Optimal repairable spareparts procurement policy under total business volume discount environment. Reliability Engineering \& System Safety, 159, 276-282. https://doi.org/10.1016/j.ress.2016.10.034

Park, S. J., Ok, C., \& Ha, C. (2017). A stochastic simulation-based holistic evaluation approach with DEA for vendor selection. Computers \& Operations Research, 100, 368-378. https://doi.org/10.1016/j.cor.2017.08.005

Razmi, J., \& Maghool, E. (2010). Multi-item supplier selection and lot-sizing planning under multiple price discounts using augmented e-constraint and Tchebycheff method. International Journal of Advanced Manufacturing Technology, 49(1-4), 379-392. https://doi.org/10.1007/s00170-009-2392-1

Riedl, D. F., Kaufmann, L., Zimmermann, C., \& Perols, J. L. (2013). Reducing uncertainty in supplier selection decisions: antecedents and outcomes of procedural rationality. Journal of Operations Management, 31(1-2), 24-36. https://doi.org/10.1016/j.jom.2012.10.003

Sabouhi, F., Pishvaee, M. S., \& Pishvaee, M. S. (2018). Resilient supply chain design under operational and disruption risks considering quantity discount: A case study of pharmaceutical supply chain. Computers \& Industrial Engineering, 126, 657-672. https://doi.org/10.1016/j.cie.2018.10.001

Sakawa, M. (1993). Fuzzy sets and interactive multiobjective optimization (pp. 71-101). Plenum Press. https://doi.org/10.1007/978-1-4899-1633-4

Saradhi, B. P., Shankar, N. R., \& Suryanarayana, C. (2016). Novel distance measure in fuzzy TOPSIS for supply chain strategy based supplier selection. Mathematical Problems in Engineering, 1, 1-17. https://doi.org/10.1155/2016/7183407

Shadkam, E., \& Bijari, M. (2017). Multi-objective simulation optimization for selection and determination of order quantity in supplier selection problem under uncertainty and quality criteria. International Journal of Advanced Manufacturing Technology, 93(1-4), 161-173. https://doi.org/10.1007/s00170-015-7986-1

Stein, J. (2011). Ford purchasing exec behrendt: Consolidation still necessary in supply base. Crain's Detroit Business. http://www.crainsdetroit.com/article/20110803/FREE/110809962/fordpurchasingexec-behrendt-consolidation-still-necessary-in-supply-base

Stević, Ž., Tanackov, I., Vasiljević, M., Novarlić, B., \& Stojić, G. (2016). An integrated fuzzy AHP and topsis model for supplier evaluation. Serbian Journal of Management, 11(1), 15-27. https://doi.org/10.5937/sjm11-10452

Sturgeon, T. J., Memedovic, O., Biesebroeck, J. V., \& Gereffi, G. (2013). Globalisation of the automotive industry: main features and trends. International Journal of Technological Learning Innovation \& Development, 2(1), 7-24. https://doi.org/10.1504/IJTLID.2009.021954

Taleizadeh, A. A., Stojkovska, I., \& Pentico, D. W. (2015). An economic order quantity model with partial backordering and incremental discount. Computers and Industrial Engineering, 82, 21-32. https://doi.org/10.1016/j.cie.2015.01.005

Talluri, S., Decampos, H. A., \& Hult, G. T. M. (2013). Supplier rationalization: a sourcing decision model. Decision Sciences, 44(1), 57-86. https://doi.org/10.1111/j.1540-5915.2012.00390.x 
Tian, G., Zhang, H., Feng, Y., Jia, H., Zhang, C., \& Jiang, Z., et al. (2017). Operation patterns analysis of automotive components remanufacturing industry development in China. Journal of Cleaner Production, 164, 1363-1375. https://doi.org/10.1016/j.jclepro.2017.07.028

Tiwari, R. N., Dharmar, S., \& Rao, J. R. (1987). Fuzzy goal programming-an additive model. Fuzzy Sets and Systems, 24(1), 27-34. https://doi.org/10.1016/0165-0114(87)90111-4

Trautrims, A., Maccarthy, B., \& Okade, C. (2017). Building an innovation-based supplier portfolio: the use of patent analysis in strategic supplier selection in the automotive sector. International Journal of Production Economics, 194, 228-236. https://doi.org/10.1016/j.ijpe.2017.05.008

Tsai, W. C., \& Wang, C. H. (2010). Decision making of sourcing and order allocation with price discounts. Journal of Manufacturing Systems, 29(1), 47-54. https://doi.org/10.1016/j.jmsy.2010.08.002

Ucal Sari, I. (2018) Development of an integrated discounting strategy based on vendors expectations using FAHP and fuzzy goal programming. Technological and Economic Development of Economy, 24(2), 635-652. https://doi.org/10.3846/20294913.2016.1213205

Wang, H. H., Yu, Y. M., Zhang, W., \& Hua, Z. S. (2019). Procurement strategies for lost-sales inventory systems with all-units discounts. European Journal of Operational Research, 272(2), 539-548. https://doi.org/10.1016/j.ejor.2018.06.053

Wu, J. (2015). A SD-IITFOWA operator and TOPSIS based approach for MAGDM problems with intuitionistic trapezoidal fuzzy numbers. Technological and Economic Development of Economy, 21(1), 28-47. https://doi.org/10.3846/20294913.2014.946982

Yang, W., Chen, Z. P., \& Zhang, F. (2017). New group decision making method in intuitionistic fuzzy setting based on TOPSIS. Technological and Economic Development of Economy, 23(3), 441-461. https://doi.org/10.3846/20294913.2015.1072754

Yu, M. C., \& Lin, H. C. (2012). Fuzzy multi-objective vendor selection under lean procurement. European Journal of Operational Research, 219(2), 305-311. https://doi.org/10.1016/j.ejor.2011.12.028

Zadeh, L. A. (1965). Fuzzy sets. Information \& Control, 8(3), 338-353. https://doi.org/10.1016/S0019-9958(65)90241-X

Zarbakhshnia, N., \& Jaghdani, T. J. (2018). Sustainable supplier evaluation and selection with a novel two-stage DEA model in the presence of uncontrollable inputs and undesirable outputs: a plastic case study. The International Journal of Advanced Manufacturing Technology, 97, 2933-2945. https://doi.org/10.1007/s00170-018-2138-Z

Zhang, J. L., \& Chen, J. (2013). Supplier selection and procurement decisions with uncertain demand, fixed selection costs and quantity discounts. Computers \& Operations Research, 40(11), 2703-2710. https://doi.org/10.1016/j.cor.2013.05.016

Zhou, X., Pedrycz, W., Kuang, Y., \& Zhang, Z. (2016). Type-2 fuzzy multi-objective DEA model: an application to sustainable supplier evaluation. Applied Soft Computing, 46, 424-440. https://doi.org/10.1016/j.asoc.2016.04.038

Zimmermann, H. J. (1978). Fuzzy programming and linear programming with several objective functions. Fuzzy Sets \& Systems, 1(1), 45-55. https://doi.org/10.1016/0165-0114(78)90031-3 


\section{APPENDIX}

\section{Data of the case}

Table 22. Original inputs and outputs data for intake air pressure sensor

\begin{tabular}{|c|c|c|c|c|c|c|c|c|c|c|c|}
\hline \multirow{2}{*}{ Supplier } & \multicolumn{9}{|c|}{ Input } & \multicolumn{5}{|c|}{ Output } \\
\cline { 2 - 13 } & S1 & S2 & Q1 & C1 & T1 & Q2 & T3 & T2 & S3 & C2 & Q3 \\
\hline 1 & 8.1 & 4.8 & 14.6 & 7.8 & 9.8 & 9.6 & 4.8 & 9.2 & 5 & 4.8 & 14.8 \\
\hline 2 & 8.3 & 4.5 & 12.9 & 7.9 & 9.2 & 9.9 & 4.9 & 9 & 4.8 & 4.2 & 12.5 \\
\hline 3 & 6.3 & 4.1 & 14.3 & 7.8 & 8.9 & 8.6 & 4.3 & 8.2 & 5 & 4.4 & 13.4 \\
\hline 4 & 9.8 & 3.7 & 13.3 & 9.9 & 9.3 & 9.7 & 4.5 & 10 & 5 & 4.8 & 14.3 \\
\hline 6 & 8 & 4.9 & 13.5 & 7.9 & 8.7 & 9.8 & 4 & 7.8 & 3.7 & 3.9 & 12.1 \\
\hline 7 & 9.9 & 4.8 & 14 & 9.5 & 9.5 & 9.5 & 4.8 & 7.5 & 4.2 & 4.3 & 14.5 \\
\hline 9 & 8.4 & 4.5 & 13.4 & 7.7 & 8.5 & 8.6 & 4.3 & 9.1 & 5 & 4.7 & 11.5 \\
\hline 11 & 9.3 & 4.9 & 12.5 & 8.1 & 9.5 & 9.8 & 5 & 10 & 4.7 & 3.6 & 13.8 \\
\hline 13 & 8.4 & 4.7 & 13.9 & 7.5 & 9.7 & 9.5 & 4.7 & 8.2 & 3.3 & 4.3 & 13 \\
\hline 16 & 7.6 & 4.9 & 12.6 & 8.2 & 8 & 8.5 & 4.9 & 7.7 & 3.5 & 4.2 & 12.8 \\
\hline 18 & 6.7 & 4.8 & 14.4 & 7.9 & 9.7 & 9.7 & 4.8 & 8.9 & 4 & 4.1 & 14.9 \\
\hline 19 & 8.7 & 4.1 & 14.5 & 8.2 & 9.8 & 8.7 & 4.1 & 9.5 & 3.7 & 4 & 12.8 \\
\hline 21 & 7.9 & 4.9 & 13 & 8.8 & 8 & 9.7 & 4.8 & 7.2 & 4 & 4.8 & 13.2 \\
\hline 23 & 7.1 & 3.9 & 14.6 & 7.9 & 9.8 & 9.1 & 4.5 & 8.1 & 4.6 & 4.3 & 14.3 \\
\hline 24 & 8.3 & 4.9 & 14.3 & 7.9 & 9.1 & 8.9 & 4.9 & 7 & 4 & 4.4 & 12.3 \\
\hline 26 & 9.1 & 4.1 & 13.5 & 7.8 & 9.5 & 9.5 & 4.7 & 8.3 & 5 & 4.6 & 12.2 \\
\hline 28 & 9.7 & 4.5 & 14.2 & 8.7 & 9.5 & 9.3 & 4.6 & 8 & 4.5 & 4.6 & 13.1 \\
\hline 30 & 9.8 & 3.9 & 9.9 & 9.3 & 8.7 & 9 & 4.2 & 7.8 & 4.3 & 4.5 & 14.6 \\
\hline
\end{tabular}

Table 23. Original inputs and outputs data for oil injection nozzle

\begin{tabular}{|c|c|c|c|c|c|c|c|c|c|c|c|}
\hline \multirow{2}{*}{ Supplier } & \multicolumn{6}{|c|}{ Input } & \multicolumn{5}{|c|}{ Output } \\
\hline & $\mathrm{S}^{*}$ & $\mathrm{~S}^{*}$ & $\mathrm{Q} 1^{\star}$ & $\mathrm{C}^{*}$ & $\mathrm{~T}^{*}$ & $\mathrm{Q}^{*}$ & $\mathrm{Q}^{*}$ & $\mathrm{~S}^{*}$ & $\mathrm{C} 2^{*}$ & $\mathrm{~S} 4^{*}$ & $\mathrm{C} 3^{*}$ \\
\hline 1 & 8.2 & 4.7 & 9.2 & 7.9 & 13.7 & 14.4 & 13.5 & 4.9 & 4.7 & 4.7 & 4.7 \\
\hline 4 & 9.9 & 4.5 & 8.3 & 9.8 & 12.5 & 14.6 & 13.9 & 5 & 4.8 & 4.6 & 4.5 \\
\hline 5 & 8.3 & 3.9 & 8.4 & 7.9 & 13.3 & 14.5 & 14.7 & 4.1 & 4.7 & 4.7 & 3.9 \\
\hline 7 & 9.7 & 4.6 & 9.3 & 9.4 & 13.5 & 14.7 & 13.7 & 4.2 & 4.4 & 4.4 & 4.7 \\
\hline 8 & 6.5 & 4.9 & 8.1 & 8 & 14.1 & 11.3 & 12.6 & 4.3 & 4.5 & 4.6 & 4.1 \\
\hline 10 & 8.4 & 4.7 & 7.5 & 8.5 & 14.2 & 14.8 & 14.8 & 3.8 & 4.3 & 4.4 & 4.8 \\
\hline 11 & 9.2 & 4.1 & 8.3 & 8.3 & 13.6 & 14.7 & 12.3 & 4.7 & 3.6 & 3.9 & 4.3 \\
\hline 12 & 8.3 & 3.7 & 7.9 & 7.5 & 12.7 & 13.3 & 13.5 & 4 & 4.1 & 4.8 & 4.4 \\
\hline 14 & 8 & 4.7 & 8.7 & 9.2 & 13.8 & 13.5 & 13.3 & 3.8 & 3.9 & 4.7 & 4.1 \\
\hline 15 & 8.5 & 4.2 & 8.9 & 8.1 & 13.2 & 14.1 & 14.1 & 4.3 & 4.5 & 4.4 & 3.9 \\
\hline 17 & 7.3 & 3.5 & 8.1 & 7.9 & 12.9 & 12.2 & 13.6 & 3.7 & 3.9 & 4.3 & 4.1 \\
\hline 19 & 8.8 & 3.9 & 9.7 & 8.3 & 13.5 & 14.8 & 14.5 & 3.7 & 4 & 4.5 & 4.5 \\
\hline 20 & 8.6 & 4.8 & 9.8 & 8.3 & 14.7 & 14.6 & 14.6 & 4.6 & 4 & 4.6 & 3.7 \\
\hline 21 & 7.7 & 4.7 & 7.1 & 8.8 & 14.1 & 14.2 & 14.2 & 4 & 4.8 & 4.6 & 3.8 \\
\hline 22 & 7.9 & 4.5 & 8.1 & 7.9 & 12.9 & 14.5 & 14.7 & 4.2 & 4.3 & 4.2 & 3.6 \\
\hline
\end{tabular}


End of Table 23

\begin{tabular}{|c|c|c|c|c|c|c|c|c|c|c|c|}
\hline \multirow{2}{*}{ Supplier } & \multicolumn{7}{|c|}{ Input } & \multicolumn{5}{|c|}{ Output } \\
\cline { 2 - 14 } & $\mathrm{S1}^{*}$ & $\mathrm{S2}^{*}$ & $\mathrm{Q}^{*}$ & $\mathrm{C1}^{*}$ & $\mathrm{~T}^{*}$ & $\mathrm{Q}^{*}$ & $\mathrm{Q}^{*}$ & $\mathrm{S3}^{*}$ & $\mathrm{C}^{*}$ & $\mathrm{~S}^{*}$ & $\mathrm{C}^{*}$ \\
\hline 24 & 8.4 & 4.7 & 9.5 & 7.8 & 13.5 & 12.5 & 12.5 & 4 & 4.4 & 4.5 & 4.5 \\
\hline 25 & 7.4 & 4.6 & 9.4 & 8.2 & 14.3 & 11.4 & 14.5 & 3.6 & 3.7 & 4.1 & 3.8 \\
\hline 27 & 9.4 & 4.1 & 6.5 & 8.5 & 13.1 & 14.3 & 14.3 & 3.7 & 4.6 & 4.4 & 4.2 \\
\hline 28 & 9.6 & 4.7 & 7.7 & 8.7 & 13.2 & 14.5 & 13.5 & 4.5 & 4.6 & 4.5 & 3.9 \\
\hline 29 & 9.4 & 4.8 & 8.2 & 7 & 13.3 & 13.4 & 14.8 & 3.8 & 3.9 & 4.9 & 4.1 \\
\hline
\end{tabular}

Table 24. Original inputs and outputs data for oxygen sensor

\begin{tabular}{|c|c|c|c|c|c|c|c|c|c|c|c|}
\hline \multirow{2}{*}{ Supplier } & \multicolumn{7}{|c|}{ Input } & \multicolumn{5}{|c|}{ Output } \\
\cline { 2 - 14 } & S1 & S2 & Q1 & C1 & T1 & Q2 & T3 & T2 & S3 & C2 & Q3 \\
\hline 2 & 8.2 & 4.6 & 12.8 & 7.8 & 9.1 & 9.8 & 4.8 & 9.1 & 4.7 & 4.1 & 12.6 \\
\hline 4 & 9.7 & 3.8 & 13.4 & 9.8 & 9.4 & 9.8 & 4.6 & 9.9 & 4.9 & 4.9 & 14.2 \\
\hline 6 & 8.1 & 4.8 & 13.6 & 7.8 & 8.6 & 9.7 & 3.9 & 7.7 & 3.6 & 3.8 & 12.2 \\
\hline 7 & 9.8 & 4.7 & 14.1 & 9.6 & 9.6 & 9.6 & 4.9 & 7.6 & 4.3 & 4.5 & 14.6 \\
\hline 8 & 6.6 & 5 & 8.7 & 8.2 & 8 & 7.5 & 3.5 & 8 & 4.3 & 4.5 & 13.5 \\
\hline 9 & 8.5 & 4.6 & 13.5 & 7.8 & 8.6 & 8.7 & 4.5 & 9.2 & 4.9 & 4.6 & 11.6 \\
\hline 11 & 9.4 & 4.8 & 12.6 & 8.2 & 9.6 & 9.9 & 4.9 & 9.9 & 4.8 & 3.7 & 13.9 \\
\hline 12 & 8.5 & 3.9 & 11.9 & 7.7 & 9 & 8.9 & 4.5 & 8 & 4 & 4.1 & 4.3 \\
\hline 14 & 8.2 & 5 & 11.8 & 9.1 & 7 & 8.8 & 4.9 & 9 & 3.7 & 3.9 & 13.3 \\
\hline 15 & 8.6 & 5 & 12.8 & 8.2 & 9 & 9.4 & 3.5 & 9.2 & 4.3 & 4.5 & 13.5 \\
\hline 17 & 7.4 & 3.6 & 12.1 & 7.8 & 9 & 8 & 3.6 & 8.5 & 3.7 & 3.9 & 13 \\
\hline 18 & 6.8 & 4.9 & 14.5 & 8 & 9.8 & 9.8 & 4.9 & 8.8 & 3.9 & 4.2 & 14.8 \\
\hline 21 & 7.8 & 4.8 & 13.1 & 8.9 & 8.1 & 9.6 & 4.9 & 7.3 & 4.1 & 4.7 & 13.1 \\
\hline 23 & 7 & 3.8 & 14.5 & 7.8 & 9.9 & 9 & 4.4 & 8 & 4.5 & 4.2 & 14.2 \\
\hline 25 & 7.4 & 4.1 & 11.9 & 8.2 & 7 & 7.6 & 4.7 & 7.9 & 3.6 & 3.7 & 13.8 \\
\hline 26 & 9.2 & 4.2 & 13.6 & 7.9 & 9.6 & 9.6 & 4.6 & 8.2 & 4.9 & 4.7 & 12.3 \\
\hline 28 & 9.8 & 4.6 & 14.3 & 8.8 & 9.6 & 9.2 & 4.7 & 7.9 & 4.6 & 4.7 & 13.2 \\
\hline 29 & 9.3 & 5 & 9.8 & 7.2 & 7 & 8.9 & 4 & 7 & 3.7 & 3.9 & 13 \\
\hline 30 & 9.9 & 3.8 & 9.8 & 9.4 & 8.8 & 8.9 & 4.3 & 7.7 & 4.2 & 4.6 & 14.7 \\
\hline
\end{tabular}

Table 25. Original inputs and outputs data for crankshaft

\begin{tabular}{|c|c|c|c|c|c|c|c|c|c|c|c|}
\hline \multirow{2}{*}{ Supplier } & \multicolumn{7}{|c|}{ Input } & \multicolumn{6}{|c|}{ Output } \\
\cline { 2 - 13 } & $\mathrm{S}^{*}$ & $\mathrm{~S}^{*}$ & $\mathrm{Q}^{*}$ & $\mathrm{C}^{*}$ & $\mathrm{~T}^{*}$ & $\mathrm{Q}^{*}$ & $\mathrm{Q}^{*}$ & $\mathrm{S3}^{*}$ & $\mathrm{C}^{*}$ & S4$^{*}$ & $\mathrm{C}^{*}$ \\
\hline 1 & 8 & 4.9 & 9.1 & 7.8 & 13.6 & 14.5 & 13.6 & 5 & 4.8 & 4.9 & 4.6 \\
\hline 3 & 6.4 & 4 & 9.5 & 7.8 & 13.5 & 12.9 & 14.3 & 5 & 4.4 & 4.9 & 4.2 \\
\hline 5 & 8.4 & 3.8 & 8.3 & 7.8 & 13.4 & 14.6 & 14.8 & 4.2 & 4.8 & 4.8 & 3.8 \\
\hline 7 & 9.6 & 4.9 & 9.4 & 9.6 & 13.6 & 14.8 & 13.8 & 4.3 & 4.5 & 4.6 & 4.8 \\
\hline 9 & 8.5 & 4.4 & 8.9 & 7.9 & 13.6 & 13.9 & 12.3 & 5 & 4.7 & 4.5 & 4 \\
\hline 10 & 8.5 & 4.8 & 7.4 & 8.6 & 14.3 & 14.9 & 14.9 & 3.7 & 4.2 & 4.5 & 4.9 \\
\hline 12 & 8.4 & 3.8 & 7.8 & 7.6 & 12.8 & 13.4 & 13.6 & 3.9 & 4.2 & 4.9 & 4.5 \\
\hline 14 & 8.1 & 4.8 & 8.9 & 9.3 & 13.9 & 13.6 & 13.4 & 3.9 & 3.8 & 4.8 & 4.2 \\
\hline
\end{tabular}


End of Table 25

\begin{tabular}{|c|c|c|c|c|c|c|c|c|c|c|c|}
\hline \multirow{2}{*}{ Supplier } & \multicolumn{6}{|c|}{ Input } & \multicolumn{5}{|c|}{ Output } \\
\hline & $\mathrm{S} 1^{*}$ & $\mathrm{~S} 2^{*}$ & $\mathrm{Q}^{*}$ & $\mathrm{Cl}^{\star}$ & $\mathrm{T} 1^{*}$ & $\mathrm{Q}^{*}$ & $\mathrm{Q}^{*}$ & $\mathrm{~S}^{*}{ }^{*}$ & $\mathrm{C} 2^{\star}$ & $\mathrm{S} 4^{*}$ & $\mathrm{C} 3^{*}$ \\
\hline 16 & 7.6 & 4.8 & 7.7 & 8.2 & 13.7 & 14.8 & 12.3 & 3.5 & 4.2 & 4.5 & 3.5 \\
\hline 18 & 6.9 & 4.7 & 9.7 & 7.8 & 13.9 & 14.6 & 14.9 & 4 & 4.1 & 3.9 & 3.8 \\
\hline 20 & 8.7 & 4.9 & 9.9 & 8.4 & 14.8 & 14.7 & 14.7 & 4.7 & 3.9 & 4.7 & 3.8 \\
\hline 22 & 7.8 & 4.6 & 8 & 7.8 & 12.8 & 14.6 & 14.6 & 4.3 & 4.2 & 4.3 & 3.7 \\
\hline 23 & 7.2 & 4.1 & 9.7 & 7.9 & 14.3 & 13.6 & 14.5 & 4.6 & 4.3 & 4.6 & 4.3 \\
\hline 25 & 7.4 & 4.6 & 9.4 & 8.2 & 14.3 & 11.4 & 14.5 & 3.6 & 3.7 & 4.1 & 3.8 \\
\hline 27 & 9.5 & 4.2 & 6.6 & 8.6 & 13.2 & 14.2 & 14.3 & 3.7 & 4.6 & 4.4 & 4.2 \\
\hline 29 & 9.5 & 4.9 & 8.3 & 7.1 & 13.2 & 13.3 & 14.9 & 3.9 & 3.8 & 4.8 & 4.2 \\
\hline
\end{tabular}

Table 26. Comparative and diversity performance for intake air pressure sensor

\begin{tabular}{|c|c|c|c|c|c|}
\hline Supplier & CP & DP & Supplier & CP & DP \\
\hline 1 & 0.88 & 0.60 & 16 & 0.51 & 0.69 \\
\hline 2 & 0.67 & 0.61 & 18 & 0.73 & 0.62 \\
\hline 3 & 0.50 & 0.73 & 19 & 0.55 & 0.62 \\
\hline 4 & 0.80 & 0.42 & 21 & 0.62 & 0.62 \\
\hline 6 & 0.49 & 0.73 & 23 & 0.61 & 0.68 \\
\hline 7 & 0.81 & 0.58 & 24 & 0.59 & 0.67 \\
\hline 9 & 0.54 & 0.79 & 26 & 0.64 & 0.71 \\
\hline 11 & 0.82 & 0.55 & 28 & 0.71 & 0.71 \\
\hline 13 & 0.63 & 0.76 & 30 & 0.59 & 0.61 \\
\hline
\end{tabular}

Note: CP - Comparative performance; DP - diversity performance.

Table 27. Comparative and diversity performance for oil injection nozzle

\begin{tabular}{|c|c|c|c|c|c|}
\hline Supplier & CP & DP & Supplier & CP & DP \\
\hline 1 & 0.86 & 0.60 & 17 & 0.48 & 0.81 \\
\hline 4 & 0.89 & 0.44 & 19 & 0.73 & 0.62 \\
\hline 5 & 0.69 & 0.73 & 20 & 0.82 & 0.52 \\
\hline 7 & 0.86 & 0.57 & 21 & 0.71 & 0.64 \\
\hline 8 & 0.62 & 0.68 & 22 & 0.61 & 0.77 \\
\hline 10 & 0.77 & 0.59 & 24 & 0.66 & 0.67 \\
\hline 11 & 0.56 & 0.73 & 25 & 0.55 & 0.80 \\
\hline 12 & 0.56 & 0.81 & 27 & 0.63 & 0.80 \\
\hline 14 & 0.64 & 0.71 & 28 & 0.72 & 0.73 \\
\hline 15 & 0.67 & 0.79 & 29 & 0.65 & 0.65 \\
\hline
\end{tabular}

Note: CP - Comparative performance; DP - diversity performance. 
Table 28. Comparative and diversity performance for oxygen sensor

\begin{tabular}{|c|c|c|c|c|c|}
\hline Supplier & CP & DP & Supplier & CP & DP \\
\hline 2 & 0.73 & 0.78 & 17 & 0.45 & 0.77 \\
\hline 4 & 0.86 & 0.46 & 18 & 0.79 & 0.64 \\
\hline 6 & 0.55 & 0.80 & 21 & 0.70 & 0.68 \\
\hline 7 & 0.86 & 0.58 & 23 & 0.63 & 0.68 \\
\hline 8 & 0.57 & 0.66 & 25 & 0.45 & 0.82 \\
\hline 9 & 0.71 & 0.68 & 26 & 0.76 & 0.62 \\
\hline 11 & 0.84 & 0.56 & 28 & 0.83 & 0.61 \\
\hline 12 & 0.48 & 0.74 & 29 & 0.52 & 0.79 \\
\hline 14 & 0.65 & 0.62 & 30 & 0.63 & 0.63 \\
\hline 15 & 0.74 & 0.62 & & & \\
\hline
\end{tabular}

Note: CP - Comparative performance; DP - diversity performance.

Table 29. Comparative and diversity performance for crankshaft

\begin{tabular}{|c|c|c|c|c|c|}
\hline Supplier & CP & DP & Supplier & CP & DP \\
\hline 1 & 0.81 & 0.55 & 16 & 0.48 & 0.79 \\
\hline 3 & 0.67 & 0.62 & 18 & 0.59 & 0.70 \\
\hline 5 & 0.69 & 0.66 & 20 & 0.85 & 0.51 \\
\hline 7 & 0.90 & 0.47 & 22 & 0.58 & 0.80 \\
\hline 9 & 0.66 & 0.68 & 23 & 0.70 & 0.70 \\
\hline 10 & 0.69 & 0.67 & 25 & 0.48 & 0.76 \\
\hline 12 & 0.55 & 0.78 & 27 & 0.61 & 0.59 \\
\hline 14 & 0.62 & 0.62 & 29 & 0.62 & 0.60 \\
\hline
\end{tabular}

Table 30. Triangular fuzzy capacity of suppliers for components A-D

\begin{tabular}{|c|c|c|c|c|c|c|c|c|c|c|c|c|}
\hline \multirow{2}{*}{ Supplier } & \multicolumn{4}{|c|}{ A } & \multicolumn{4}{c|}{ C } & \multicolumn{3}{c|}{ B } & \multicolumn{3}{c|}{ D } \\
\cline { 2 - 14 } & P & M & O & P & M & O & P & M & O & P & M & O \\
\hline 1 & 1350 & 1400 & 1700 & - & - & - & 1450 & 1600 & 1850 & 1350 & 1500 & 1700 \\
\hline 4 & 1500 & 1750 & 2000 & 1300 & 1500 & 1750 & 1350 & 1650 & 1750 & - & - & - \\
\hline 7 & 1250 & 1500 & 1750 & 1450 & 1650 & 1800 & 1500 & 1750 & 1900 & 1250 & 1400 & 1500 \\
\hline 10 & - & - & - & - & - & - & - & - & - & - & - & - \\
\hline 11 & 1500 & 1700 & 1800 & 1550 & 1700 & 1900 & - & - & - & - & - & - \\
\hline 20 & - & - & - & - & - & - & 1550 & 1800 & 2000 & 1550 & 1700 & 1900 \\
\hline 23 & - & - & - & - & - & - & - & - & - & 1750 & 1950 & 2100 \\
\hline 28 & - & - & - & 1250 & 1400 & 1600 & - & - & - & - & - & - \\
\hline
\end{tabular}

Note: P - Pessimistic; M - Most likely; O - Optimistic. 
Table 31. Defect rate for the components A-D

\begin{tabular}{|c|c|c|c|c|}
\hline \multirow{2}{*}{ Supplier } & \multicolumn{4}{|c|}{ Defect rate for components } \\
\cline { 2 - 5 } & $\mathrm{A}$ & $\mathrm{C}$ & $\mathrm{B}$ & $\mathrm{D}$ \\
\hline 1 & 0.05 & - & 0.006 & 0.002 \\
\hline 4 & 0.01 & 0.03 & 0.005 & - \\
\hline 7 & 0.039 & 0.025 & 0.004 & 0.003 \\
\hline 11 & 0.015 & 0.045 & - & - \\
\hline 20 & - & - & 0.007 & 0.005 \\
\hline 23 & - & - & - & - \\
\hline 28 & - & 0.02 & - & 008 \\
\hline
\end{tabular}

Table 32. Fixed and variable costs of components A-D

\begin{tabular}{|c|c|c|c|c|c|c|}
\hline \multirow{2}{*}{ Supplier } & \multicolumn{3}{|c|}{ Unit variable cost of each component (RMB) } & \multirow{2}{*}{$\operatorname{Min}_{j}$} & \multirow{2}{*}{ Fixed cost (RMB) } \\
\cline { 2 - 5 } & $\mathrm{A}$ & $\mathrm{C}$ & $\mathrm{B}$ & $\mathrm{D}$ & & \\
\hline 1 & 173 & - & 35 & 45 & 45 & 1200 \\
\hline 4 & 145 & 213 & 31 & - & 65 & 1000 \\
\hline 7 & 149 & 219 & 39 & 42 & 50 & 1550 \\
\hline 11 & 176 & 220 & - & - & 55 & 1150 \\
\hline 20 & - & - & 37 & 40 & 60 & 1450 \\
\hline 23 & - & - & - & 48 & 40 & 1250 \\
\hline 28 & - & 230 & - & - & 70 & 1350 \\
\hline
\end{tabular}

Note: $\mathrm{Min}_{j}-$ The minimum order quantities for component if purchasing from supplier $j$.

Table 33. Triangular fuzzy lead times for components A-D

\begin{tabular}{|c|c|c|c|c|}
\hline \multirow{2}{*}{ Supplier } & \multicolumn{4}{|c|}{ Delivery time } \\
\cline { 2 - 5 } & A & C & B & D \\
\hline 1 & $(5810)$ & - & $(5711)$ & $(6913)$ \\
\hline 4 & $(5712)$ & $(469)$ & $(4710)$ & - \\
\hline 7 & $(2610)$ & $(5712)$ & $(469)$ & $(4813)$ \\
\hline 11 & $(4610)$ & $(269)$ & - & - \\
\hline 20 & - & - & $(3713)$ & $(469)$ \\
\hline 23 & - & - & - & - \\
\hline 28 & - & $(5611)$ & - & \\
\hline
\end{tabular}

Table 34. All-unit quantity discounts provided by candidate suppliers

\begin{tabular}{|c|l|l|}
\hline Supplier & \multicolumn{1}{|c|}{ Quantity } & \multicolumn{1}{|c|}{ Discounts } \\
\hline 1 & {$[0,1100) ;[1100,2200) ;[2200,3000) ;[3000,+\infty)$} & $0.0 \% ; 7.2 \% ; 11.5 \% ; 15.6 \%$ \\
\hline 4 & {$[0,650) ;[650,1650) ;[1650,2600) ;[2600,+\infty)$} & $0.0 \% ; 6.2 \% ; 9.5 \% ; 12.2 \%$ \\
\hline 7 & {$[0,1230) ;[1230,2230) ;[2230,3200) ;[3200,+\infty)$} & $0.0 \% ; 8.3 \% ; 11.4 \% ; 15.7 \%$ \\
\hline 11 & {$[0,580) ;[580,1580) ;[1580,2750) ;[2750,+\infty)$} & $0.0 \% ; 9.0 \% ; 12.3 \% ; 17.3 \%$ \\
\hline 20 & {$[0,780) ;[780,1780) ;[1780,2800) ;[2800,+\infty)$} & $0.0 \% ; 6.8 \% ; 9.9 \% ; 13.3 \%$ \\
\hline 23 & {$[0,728) ;[728,1725) ;[1725,2755) ;[2755,+\infty)$} & $0.0 \% ; 5.6 \% ; 7.6 \% ; 11.1 \%$ \\
\hline 28 & {$[0,850) ;[850,1850) ;[1850,2800) ;[2800,+\infty)$} & $0.0 \% ; 5.5 \% ; 9.3 \% ; 12.7 \%$ \\
\hline
\end{tabular}

